\title{
Monetary, financial and fiscal stability in the East African Community: ready for a monetary union?
}

\author{
Laetitia Lepetit*
}

\author{
Clovis Rugemintwari ${ }^{\dagger}$
}

Frank Strobel ${ }^{\ddagger}$

October 17, 2012

\begin{abstract}
We examine prospects for a monetary union in the East African Community (EAC) by developing a stylized model of policymakers' decision problem that allows for uncertain benefits derived from monetary, financial and fiscal stability, and then calibrating the model for the EAC for the period 2003-2010. When policymakers properly allow for uncertainty, none of the countries wants to pursue a monetary union based on either monetary or financial stability grounds, and only Rwanda might favor it on fiscal stability grounds; we argue that robust institutional arrangements assuring substantial improvements in monetary, financial and fiscal stability are needed to compensate.

Keywords: monetary union, East African Community, financial stability, real option

JEL Classification: E58, F33, O55

\footnotetext{
*LAPE, Université de Limoges, Limoges, France. E-mail: laetitia.lepetit@unilim.fr

†LAPE, Université de Limoges, Limoges, France. E-mail: clovis.rugemintwari@unilim.fr

$\ddagger$ Department of Economics, University of Birmingham, Birmingham, UK. E-mail: f.strobel@bham.ac.uk
} 


\section{Introduction}

The East African Community (EAC), currently consisting of Burundi, Kenya, Rwanda, Tanzania and Uganda, has been engaged in an ambitious integration process since its official relaunch in 2000. A customs union was set up in 2005 which became fully operational in 2010, a common market project was initiated in 2010 which is scheduled to be completed by 2015, and the EAC member countries are also in the process of further moving towards establishing a monetary union as well. Negotiations of monetary union protocols were initiated in January 2011 (EAC 2011) and are currently anticipated to be concluded by the end of 2012, making way for discussions of suitable roadmaps for a possible transition to a single currency in the region (Rusuhuzwa \& Masson 2012). Our paper aims to contribute to this debate by highlighting several important issues that have not been previously focussed on in the academic literature on the subject.

While there is a fair number of studies examining the feasibility or desirability of monetary unions in Africa more generally (see e.g. Debrun et al. 2011 for a survey), the literature focussing on the EAC in particular is relatively small for the time being. Most of the research focussing on the EAC examines the potential for a monetary union in the light of the Optimal Currency Area (OCA) approach which has its origins in the seminal work of Mundell (1961), McKinnon (1963) and Kenen (1969). Mkenda (2001), using data for varying periods up to 1998, examines the three original EAC member countries, Kenya, Uganda and Tanzania, and finds some support that they constitute an OCA. Buigut \& Valev (2005), on the other hand, consider this question for all five current EAC member countries using data for the period 1970-2001, with results that are rather unsupportive of these countries forming an OCA. In a similar spirit, Buigut (2011) focusses on the state of convergence across several macro measures over the period 1997-2008 for the five EAC members, whereas Kishor \& Ssozi (2011) examine their degree of business cycle synchronization over the period 1970-2007; both similarly 
conclude that the evidence for these countries representing an OCA is weak. A different methodological approach is pursued in the related but complimentary papers of Buigut \& Valev (2009) and Debrun et al. (2011). They aim to model potential benefits as well as costs associated with a monetary union by focussing on the reduction in inflation bias (in a Barro \& Gordon 1983b sense) achievable through being in a monetary union. Calibrating their model, which allows for random supply shocks to output and stochastic preferences for output stimulation, to EAC data for the period 1990-2004, Buigut \& Valev (2009) find that Uganda and Tanzania would benefit from a monetary union whereas the other countries would lose from it. Debrun et al. (2011), whose model allows for the setting of tax and seigniorage revenues to achieve optimal productive expenditure and its interaction with stabilizing monetary policy reactions to shocks, find using data covering the period 1990-2008 that Burundi and Kenya would benefit most from a monetary union in the EAC, whereas Tanzania would lose from joining it.

The methodological approach used in the present paper to assess whether the EAC is "ready" for a monetary union is related to the previous two papers, in that it builds on work in Strobel (2005, 2007) which also examine countries' willingness to join a monetary union when a time inconsistency problem in monetary policymaking causes an inflation bias to persist, but stress the importance of taking the real option associated with such monetary regime changes into account. The papers argue that, when the future evolution of policymakers' inflation preferences is uncertain in such a context, countries might find it beneficial to hold back on joining a wider monetary union due to their reluctance to commit to a largely irreversible decision that might later prove less advantageous than initially thought. This value of waiting, stemming from the real options nature of the decision problem, is well-known from the literature on irreversible investment under uncertainty, can generally be substantial and needs to be properly accounted for. ${ }^{1}$

\footnotetext{
${ }^{1}$ See e.g. McDonald/Siegel (1986) and Dixit/Pindyck (1994).
} 
In order to highlight the importance of the role of uncertainty in policymakers' decision making in this respect, we develop a stylized model of policymakers' decision problem that allows for the stochastic nature of three key areas of relevance in the decision of whether or not to join a monetary union: monetary, financial and fiscal stability. In addition to the monetary stability aspect that has so far been center stage in this context, the recent developments in the euro zone have provided ample proof that both financial and fiscal stability aspects can also have a tremendous impact on the functioning and even viability of a monetary union, even if no prior informal arrangements or even explicit institutional structures regarding the sharing of financial and fiscal risk exist in the region constituting the monetary union. Deriving the trigger values of monetary, financial and fiscal stability measures which determine whether or not policymakers find it beneficial to exercise the real option of engaging in the monetary union, we show that when policymakers properly account for the uncertainty regarding the evolution of the monetary, financial and fiscal stability measures considered, they might prove quite reluctant to go ahead with participation in a monetary union unless compensated for by potential other factors (such as institutional improvements or more transactional benefits), as the net benefits derived from being in the monetary union might later prove less advantageous than initially thought.

We then calibrate our model for the EAC, using annual data for the period 2003 to 2010, for various proxies of our respective monetary, financial and fiscal stability measures. Two key results emerge from our calibrations: firstly, the choice of proxies we consider for our monetary, financial and fiscal stability measures matters for whether or not policymakers find joining a monetary union beneficial for their particular country. Secondly, and more importantly, however, allowing for the impact of uncertainty surrounding the evolution of these measures of monetary, financial and fiscal stability generally makes policymakers significantly less eager to engage in a mone- 
tary union, unless compensated for by sufficient degrees of other benefits, such as of a transactional nature, or more importantly in our view, institutional improvements over existing national arrangements. When policymakers properly allow for the role of uncertainty in this context, we conclude that none of the countries wants to engage in a monetary union based on either monetary or financial stability considerations unless compensated for by significant relative levels of additional benefits, requiring in our view credible and robust institutional arrangements at the monetary union level assuring substantial improvements in monetary and financial stability. When looking at the fiscal stability aspect, all countries except possibly Rwanda would be reluctant to join the monetary union from this perspective when uncertainty is taken into account, unless compensated for by a sufficient relative degree of additional benefits, again asking for a sound institutional structure assuring fiscal stability in the monetary union.

Section 2 now provides some background for the EAC countries; Section 3 develops our model; Section 4 describes our calibration approach; Section 5 presents and discusses our results; and Section 6 concludes the paper.

\section{Political, economic and institutional back- ground}

The roots of the East African Community (EAC) go back to the colonial period when a customs union between Kenya and Uganda was signed in 1917, which was later joined by Tanzania (called at that time Tanganyika) in 1927. The first treaty establishing the EAC was signed in 1967; however, it collapsed a decade later in 1977 and was officially dissolved in 1983. Several reasons for the collapse of the old EAC have been put forward (Mugomba 1978, Hazlewood 1979). Firstly, there was a sentiment that the common market was more beneficial to Kenya than to Tanzania and Uganda. This can be explained by differences in the level of industrialization, with a more 
developed industrial sector in Kenya than in the two other countries. Secondly, Kenya, Tanzania and Uganda had important ideological and domestic political differences. Kenya was committed to capitalism, but internal political tensions and corruption had led to economic stagnation. On the other hand, Tanzania and Uganda pursued forms of African socialism (Ujamaa in Tanzania and Common Man's Charter in Uganda).

The region went through several political and economic shocks after the collapse of the initial EAC. However, the three countries have lately followed broadly similar policies by adopting capitalism, without any central economic coordination. In 1999, the three original partner states Kenya, Uganda and Tanzania ratified the treaty reviving the EAC, which came into force in July 2000. ${ }^{2}$ In July 2007, two more countries, Burundi and Rwanda became officially full members of the EAC, giving it its current shape of five partner states. The integration process of the EAC is embedded in Article 5(2) of its Treaty, stipulating that the "Partner States undertake to establish among themselves [...] a Customs Union, a Common Market, subsequently a Monetary Union and ultimately a Political Federation". The first of these four steps has been completed: the customs union was signed in March 2004, was launched in 2005 and became fully operational in 2010. The common market project was initiated in 2010 and is scheduled to be completed by 2015; the completion of these first two steps will allow the free movement of goods, labour, services and capital among the five member countries. The next step in this integration process is the move towards a monetary union, with negotiations of monetary union protocols having started in January 2011 which are currently anticipated to be concluded by the end of $2012 .{ }^{3}$

Before looking more closely at the decision of individual EAC member countries of whether joining a monetary union based on monetary, financial

\footnotetext{
${ }^{2}$ The treaty laying down the foundations of the current EAC can be found at $<$ http://www.eac.int/treaty/index.php $>$.

${ }^{3}$ As for a political federation, preparations are at early stages and no precise timetable has yet been given.
} 
and fiscal stability considerations may be beneficial, it is helpful to look at some more general indicators of the economic structure, the development of the financial system and the institutional environment of these countries.

All EAC countries have pursued programs to restructure their economies over the last two decades, with the help of the International Monetary Fund and the World Bank. Uganda and Rwanda were the most successful reformers (public sector reforms, trade liberalization, market and price reforms) leading to an economic expansion. These two countries display the highest average GDP growth rate in the EAC over the period 2000-2010 (see Table 1) accompanied by an increase of GDP per capita of $58 \%$ for Rwanda and $47 \%$ for Uganda (see Figure 1). This means that those two countries may ultimately catch up with Kenya which has the highest GDP per capita. Uganda and Rwanda have also had success in reducing their inflation rates to comparatively low levels of $2.3 \%$ and $4 \%$, respectively, in 2010 (see Table 1). They furthermore, together with Tanzania, have the lowest budget deficit and domestic public debt (as percentage of GDP) on average over the last decade (see Table 2).

Kenya has been affected by government mismanagement, counterproductive economic policies and corruption for decades (Heritage Foundation 2012). Political pressures lead to several breakdowns of fiscal and monetary discipline, and Kenya has on average the highest domestic public debt to GDP ratio and a high inflation rate over the period 2000-2010. Tanzania, a historically state-led economy, made progress in fostering growth over the past decade with a GDP per capita in 2010 close to Kenya's (see Table 1 and Figure 1), through implementing a large program of reforms to become more market-based. Amongst the EAC countries, Burundi is the least performing one with a GDP per capita 25\% of the ones of Kenya and Tanzania, and 35\% of those of Uganda and Rwanda. According to Heritage Foundation (2012), the repressive policy environment in Burundi makes it difficult for the private sector to create employment and sustained economic growth. Despite these 
differences, the EAC countries are fairly similar when looking at the sectoral composition of GDP (see Table 1). All are heavily dependent on agriculture, with exports being largely resource-based.

World Development Indicators on government effectiveness, control of corruption, political stability, rule of law and regulatory quality further show that there are strong disparities in terms of institutional environment between EAC countries (see Figures 2 to 6 ). Such differences can possibly go a long way towards explaining the different economic performances observed. Rwanda shows the highest degree of improvement over the last decade in terms of quality of public services, credibility of government policies, control of corruption and confidence in the rules of society.

Important differences across the EAC can furthermore be observed regarding the size and the development of the financial sector. While EAC financial systems are all concentrated in commercial banking and very small in relation to the economy, the level of development of capital markets varies greatly. Kenya has a relatively well-developed financial sector, Tanzania and Uganda have small stock exchanges and Burundi and Rwanda do not have a stock market at all (see Table 3). The market capitalization of the 55 listed Kenyan companies stands at about $35 \%$ of GDP, whereas that of the 11 Tanzanian and the 8 Ugandan ones is about $27 \%$ and $5.5 \%$, respectively. The development of the securities market in the EAC countries is constrained by the small number of private firms with the capacity to raise funds through the capital markets. Similarly, the demand for financial products is also relatively low.

The financial system of all EAC countries is dominated by banks. Large reforms have been implemented during the last two decades in order to liberalize the banking system, privatize state-owned banks and restructure loss making banks characterized by a high level of non performing loans (Cihak \& Podpiera 2005, UN Economic Commission for Africa 2008). The expected positive effects from liberalization in terms of savings mobilization and credit 
allocation were slow to emerge, but one can observe over the last five years a sharp acceleration in the domestic credit provided by the banking sector relative to GDP, apart from for Rwanda (see Figure 7). These reforms notwithstanding, EAC countries have overall a low level of financial intermediation and access to finance is a critical issue. As shown in Table 3, less than $30 \%$ of the population in Rwanda, Tanzania and Uganda have access to the formal financial system, whereas more than $50 \%$ of the population in Rwanda and Tanzania are completely excluded from access to financial services. In Kenya, the development of mobile banking has however increased the proportion of the population that has access to the formal banking sector to $40 \%$. Furthermore, bank deposits as a percentage of GDP are less than $35 \%$ for Burundi, Tanzania, Uganda and Rwanda and just above $50 \%$ for Kenya, well below the levels of some other African countries (e.g. $70 \%$ in South Africa).

This high level of financial exclusion could be explained by the small number of banks which operate in the EAC (see Table 3), as well as by the lack of competition between these banks. Sanya \& Gaertner (2012) show that despite the lack of formal regulatory barriers to entry, there are structural factors that enable some banks to benefit from a degree of monopoly power. More than two decades after reforms were started, the spread between lending and deposit rates is still high (above 8\%, see Table 3), reflecting this lack of competition. The banking system in Uganda shows the highest bank spread, but it is also the most robust one with the highest return on assets on average over the period 2003-2010, the highest capital adequacy and equity ratios, the lowest non performing loans to gross loans ratio and a relatively high value of the aggregate Z-score, ${ }^{4}$ reflecting a relatively low level of aggregate bank insolvency risk (see Table 4). The banking system in Kenya, which is by far the most developed in the EAC, also displays good performance with a strong decrease in the non performing loans ratio over the period 2003-

\footnotetext{
${ }^{4}$ See Section 4 for details of this measure.
} 
2010 and the highest aggregate Z-score, i.e. the lowest degree of aggregate bank insolvency risk. The banking systems in Burundi and Rwanda, on the other hand, are the smallest in the EAC and have a relatively high level of non performing loans. Lastly, there are also important differences in banking regulation across the EAC as shown in Table 5: there is no explicit deposit insurance system in Burundi and Rwanda, and there is no harmonization on activity restrictions and capital adequacy requirements throughout.

Overall, despite tremendous improvements in economic fundamentals in the EAC countries in the last decade, we still observe a substantial degree of divergence in these, supplemented with even stronger differences in the institutional environment in place in these countries.

[Insert Tables 1-5 and Figures 1-8]

\section{Policymakers' stylized decision problem}

As our first step towards examining prospects for a monetary union in the EAC, we now develop a stylized model of policymakers' decision problem regarding whether or not to join a monetary union that allows for the uncertainty arising in three key areas of importance in this context. Policymakers are assumed to be concerned with monetary $(m)$, financial $(f)$ as well as fiscal $(g)$ stability, in their own countries $(c)$ or the monetary union $(u)$ if they decide to participate in it. They face instantaneous benefit rates $\beta_{s i t}=\xi_{s i t}^{\gamma}$, where $s=m, f, g$ and $i=c, u$, that are concave, with concavity parameter $0<\gamma \leq 1$, in monetary, financial and fiscal stability measures $\xi_{m i t}, \xi_{f i t}, \xi_{g i t} \geq 0$ which are stochastic and follow geometric Brownian motions $^{5}$

$$
d \xi_{s i t}=\sigma_{s i} \xi_{s i t} d z_{s i t}, s=m, f, g, i=c, u
$$

\footnotetext{
${ }^{5}$ Strobel (2009) uses a related but less general framework limited to strictly linear benefit/loss functions.
} 
where $\sigma_{s i}>0, d z_{s i t}=\varepsilon_{s i t} \sqrt{d t}$ are increments of Wiener processes with $\varepsilon_{s i t} \sim$ $\operatorname{NID}(0,1)$, and $E_{t}\left(d z_{s c t} d z_{\text {sut }}\right)=\rho_{s} d t$ with $\rho_{s}$ the coefficient of correlation between the processes $z_{\text {sit }}$ (and $-1 \leq \rho_{s}<1$ ).

The expected present discounted value of benefits associated with monetary, financial or fiscal stability is then ${ }^{6}$

$$
B_{s i t}=E_{t} \int_{t}^{\infty} \beta_{s i \tau} e^{-\mu(\tau-t)} d \tau=\frac{\xi_{s i t}^{\gamma}}{\mu-\frac{1}{2} \sigma_{s i}^{2} \gamma(\gamma-1)}, s=m, f, g
$$

where $\mu>0$ is the (possibly subjective) discount rate, and $\mu-\frac{1}{2} \sigma_{s i}^{2} \gamma(\gamma-1)>$ 0 represents a natural convergence condition.

The decision of a country $c$ on whether or not to participate in the monetary union $u$, on monetary, financial or fiscal stability grounds, ${ }^{7}$ then involves solving the Bellman equation for the optimal stopping problem ${ }^{8}$

$F\left(B_{s u}, B_{s c}\right)=\max \left\{\left(1+\kappa_{s}\right) B_{s u}-B_{s c}, \frac{1}{\mu d t} E\left[d F\left(B_{s u}, B_{s c}\right)\right]\right\}, s=m, f, g$

where $F\left(B_{s u}, B_{s c}\right)$ is the value to country $c$ of the option of participating in the monetary union $u$, and $\left(1+\kappa_{s}\right) B_{s u}-B_{s c}$ is the expected discounted benefit from improved monetary, financial or fiscal stability of such a participation, with all potential other benefits ${ }^{9}$ captured by the proportionality factor $\kappa_{s} \geq 0$. Note that this implicitly assumes that participating in a monetary union is an irreversible process, so that the costs of possibly later leaving it, both reputational and institutional, are considered prohibitively high. ${ }^{10}$ We can then obtain

\footnotetext{
${ }^{6}$ See e.g. Dixit (1993, eq. (2.7)).

${ }^{7}$ As the relative benefits associated with monetary, financial and fiscal stability are far from straightforward to quantify jointly, we consider these decision problems separately.

${ }^{8}$ We drop time subscripts for ease of notation.

${ }^{9}$ These could e.g. be of a transactional nature or relate to institutional improvements; for a survey see De Grauwe (2012, ch. 3).

${ }^{10}$ The option of possible future monetary disintegration could in principle be allowed
} 
Proposition 1 Country c will want to exercise the option of participating in the monetary union $u$, on monetary $(m)$, financial $(f)$ or fiscal $(g)$ stability grounds, if

$$
\frac{\xi_{s u}}{\xi_{s c}} \geq \frac{\xi_{s u}^{*}}{\xi_{s c}^{*}}=\left(\frac{\beta_{s}^{+}\left(\mu-\frac{1}{2} \sigma_{s u}^{2} \gamma(\gamma-1)\right)}{\left(1+\kappa_{s}\right)\left(\beta_{s}^{+}-1\right)\left(\mu-\frac{1}{2} \sigma_{s c}^{2} \gamma(\gamma-1)\right)}\right)^{\frac{1}{\gamma}}, s=m, f, g
$$

where $\beta_{s}^{+}$is the positive root ${ }^{11}$ of the characteristic equation

$$
\begin{aligned}
\left(\sigma_{s u}^{2}-2 \rho_{s} \sigma_{s u} \sigma_{s c}+\sigma_{s c}^{2}\right) \gamma^{2} \beta_{s}^{2}-(2 \gamma & \left.\left(\sigma_{s c}^{2}-\rho_{s} \sigma_{s u} \sigma_{s c}\right)+\sigma_{s u}^{2}-\sigma_{s c}^{2}\right) \gamma \beta_{s} \\
& +\sigma_{s c}^{2} \gamma(\gamma-1)-2 \mu=0, s=m, f, g
\end{aligned}
$$

and not exercise it otherwise.

Proof. See the Appendix.

Country $c$ thus perceives exercise of the option of participating in the monetary union $u$, on monetary, financial or fiscal stability grounds, as desirable only when the current value of relative monetary, financial or fiscal stability measure $\xi_{s u} / \xi_{s c}$ is greater than (or equal to) its derived trigger value $\xi_{s u}^{*} / \xi_{s c}^{*}$; intuitively, the lower a country's monetary, financial or fiscal stability relative to the potential monetary union's, the more it stands to gain from participating in that union. While $\xi_{s u} / \xi_{s c}<\xi_{s u}^{*} / \xi_{s c}^{*}$ applies, on the other hand, country $c$ strictly prefers to leave the option of participating in the monetary union $u$ unexercised and remains outside it for the time being.

Figures 9-11 numerically illustrate the economic relevance of these results, graphing the trigger values $\xi_{u}^{*} / \xi_{c}^{*}$ derived in Proposition 1 for different parameter combinations of standard deviations $\sigma_{i}$, correlation coefficients

for as well, albeit at nontrivial analytical cost. Qualitatively, however, results would be very similar to the benchmark case considered here as long as the costs associated with later leaving the monetary union are sufficiently high, a scenario vividly illustrated by the Eurozone crisis debate of 2012.

${ }^{11}$ While $\beta_{s}^{+}$can be derived analytically, it is rather unwieldy and not too insightful for our purposes here. 
$\rho$, discount rates $\mu$, concavity parameters $\gamma$ and the proportionality factor $\kappa .^{12}$ We observe from the nontrivial magnitudes of trigger values arising that when policymakers properly account for the uncertainty surrounding the future evolution of the monetary, financial and fiscal stability measures considered, they might prove quite reluctant to go ahead with participation in a monetary union unless compensated for by potential other benefits (captured by the proportionality factor $\kappa$ ), as the associated benefits and costs might later prove less advantageous than initially thought.

\section{[Insert Figures 9-11]}

\section{Calibration approach}

To calibrate our model for the EAC, we use annual data from the EAC Statistics database $^{13}$ as our main source of data. As this data is harmonized for the five EAC member countries, data discrepancies that might stem from differences in definitions or calculations across different sources are reduced. The period over which our calibration is carried out is driven by data availability, and covers the period 2003 to 2010. Some missing data (for 2003 and 2004 for Tanzania and for 2009 for Uganda in particular) was completed from central bank reports. Our data was furthermore checked against two other data sources, International Financial Statistics (IFS) and World Development Indicators (WDI), turning out broadly comparable (with the exception of Kenya, where the inflation rate reported in the EAC database was comparatively lower for 2006-2009).

We consider various proxies for our monetary, financial and fiscal stability measures. We proxy the monetary stability measure $\xi_{m}$ by two indicators: the inverse of the (realized) inflation rate given by the consumer price index (CPI), and the inverse of the public domestic debt to GDP ratio. These

\footnotetext{
${ }^{12}$ These are consistent with Section 4's calibration.

${ }^{13}$ This is available at $<$ http://www.eac.int/statistics/index.php $>$.
} 
measures aim to capture the potential inflation bias resulting when governments try to stimulate output in the short run (the expectational Phillips curve argument) or to reduce the real value of outstanding public (domestic) debt (the governmental revenue motive). ${ }^{14}$ We find non-trivial ranges of the standard deviations $\sigma_{m c}$ used in our calibrations that go from 0.09 to 1.01, and correlation coefficients $\rho_{m}$ that range between -0.07 and 0.97 .

We also consider two proxies for our financial stability measure $\xi_{f}$ : the inverse of the bank nonperforming loans to gross loans ratio, one of the traditional financial soundness indicators used by the International Monetary Fund (IMF), and aggregate Z-score measures reflecting the overall insolvency risk faced by a country's banking sector. ${ }^{15}$ Using aggregate country data for the banking sector, we construct these aggregate Z-score measures as $Z=\left(\overline{R O A}+\overline{E Q \_T A}\right) / \sigma_{R O A}$ where $\overline{R O A}$ and $\overline{E Q \_T A}$ are three year rolling means of the return on assets and the equity to total assets ratio, and $\sigma_{R O A}$ is the three year rolling standard deviation of the return on assets. ${ }^{16}$ We observe values of the standard deviations $\sigma_{f c}$ used in our calibrations that range from 0.11 to 0.89 , and correlation coefficients $\rho_{f}$ that lie between -0.38 and 0.99 .

Lastly, we use the two following proxies for our fiscal stability measure $\xi_{g}$ : the inverse of the budget deficit (including all grants) to GDP ratio, and the inverse of the budget deficit (excluding all grants) to GDP ratio. The distinction between the two is relevant as we note from Table 2 that the government finances of Burundi and Rwanda, in particular, are strongly dependent on grants. As the level and continuity of such grants can be unpredictable, the measure excluding all grants is more "structural" in a sense than the one including them. We find values of the standard deviations $\sigma_{g c}$ used in our

\footnotetext{
${ }^{14}$ See e.g. Barro \& Gordon (1983a) and Barro (1983), respectively.

${ }^{15}$ For a survey of different approaches to constructing such aggregate Z-score measures, see Strobel (2011).

${ }^{16} \mathrm{We}$ also considered an alternative way of computing the Z-score measure, given by $Z=(\overline{R O E}+100) / \sigma_{R O E}$, where $R O E$ is the return on equity (in percent), with similar results.
} 
calibrations that go from 0.08 to 0.22 , and correlation coefficients $\rho_{g}$ that range between -0.08 and 0.88 .

The potential monetary union's monetary, financial and fiscal stability measures $\xi_{s u}$ are then constructed as the arithmetic means of the constituent countries' proxied values, weighted by domestic credit provided by the banking sector for the financial stability proxies, and (constant) GDP for the monetary and fiscal stability proxies (these were retrieved from WDI). For the monetary stability measures, this mimics a bargaining outcome over the union's monetary policy where individual member countries' votes reflect their relative size in the union. For the financial and fiscal stability measures, on the other hand, this approximates financial and fiscal risk sharing arrangements implicitly (or even explicitly) associated with the monetary union, again allowing for individual member countries' respective size.

In order to then compute the proxied trigger values of relative monetary, financial and fiscal stability measures $\xi_{s u}^{*} / \xi_{s c}^{*}$ given by Proposition 1, we derive the standard unbiased estimates ${ }^{17}$ of $\sigma_{s i}$ and $\rho_{s}$ by calculating the standard deviations and correlation coefficients for the respective transformed series $\ln \left(\xi_{t} / \xi_{t-1}\right)$ for each of our proxies. In line with discount rates applied by the World Bank and African Development Bank, we assume a (social) discount rate of $\mu=12 \%$ (see e.g. Harrison 2010), consistent with a substantial amount of myopia attached to policymaker's decision making. ${ }^{18} \mathrm{We}$ furthermore set the concavity parameter in policymaker's benefit functions at $\gamma=0.5$, reflecting the plausible assumption that the benefits policymakers derive from increased monetary, financial or fiscal stability exhibit diminishing marginal returns. ${ }^{19}$ An interesting benchmark case in our calibrations is going to be the decision problem for a policymaker that ignores the importance of uncertainty in their decision making process: it is straightforward

\footnotetext{
${ }^{17}$ See e.g. Ingersoll (1987, p. 358).

${ }^{18}$ See e.g. Strobel (2007, fn. 16); we also used alternative discount rates of 10 and $11 \%$, with similar results.

${ }^{19}$ We also used $\gamma=1$ in our calibrations, with similar results.
} 
to see that the trigger value corresponding to the one given in Proposition 1 would then simply be $\xi_{s u}^{*} / \xi_{s c}^{*}=1$ in this case.

\section{$5 \quad$ Results and discussion}

We present the results from our calibrations in Tables 6-8, examining policymakers' willingness to participate in a monetary union on monetary, financial and fiscal stability grounds, respectively. Our analysis is carried out first considering a monetary union consisting of all five current member countries of the EAC; we then alternatively examine whether the results differ when we restrict the analysis to the three original member countries that may have deeper ties by comparison. This will allow us to determine whether the addition of Burundi and Rwanda in 2007 to the EAC made the move towards a monetary union more difficult to achieve or not. In each case, we examine whether countries would be willing to participate in a given monetary union under two scenarios: firstly, where policymakers abstract from the role of uncertainty, ${ }^{20}$ and then, secondly, where they do properly account for the importance of uncertainty in the decision problem they face, in line with Proposition 1. By comparing the respective trigger values $\xi_{s u}^{*} / \xi_{s c}^{*}$ with the actual values $\xi_{s u} / \xi_{s c}$ of each criterion/proxy in the year 2010 (our reference period), we then explicitly answer the question whether each country would currently find participating in the given monetary union advantageous or not. Where they would prefer to stay outside a given monetary union for the time being, we further calculate the minimum level of relative other benefits $\kappa_{s}^{*}$ associated with being in a monetary union that would nevertheless make it worthwhile for them to participate in the monetary union after all. ${ }^{21}$

The results from our calibration considering countries' willingness to par-

\footnotetext{
${ }^{20}$ Implying a trigger value of $\frac{\xi_{s u}^{*}}{\zeta_{s c}^{*}}=1$, as noted in Section 4.

${ }^{21}$ Note that $\kappa_{s}^{*}$ is thus implicitly defined by $\xi_{s u} / \xi_{s c}=$ $\left[\left(\beta_{s}^{+}\left(\mu-\frac{1}{2} \sigma_{s u}^{2} \gamma(\gamma-1)\right)\right) /\left(\left(1+\kappa_{s}^{*}\right)\left(\beta_{s}^{+}-1\right)\left(\mu-\frac{1}{2} \sigma_{s c}^{2} \gamma(\gamma-1)\right)\right)\right]^{\frac{1}{\gamma}}$ from Proposition 1 , or $\kappa_{s}^{*}=\xi_{s c} / \xi_{s u}-1$ for the certainty case.
} 
ticipate in a monetary union on monetary stability grounds are presented in Table 6. When policymakers ignore the role of uncertainty in the decision of whether or not to join a monetary union consisting of all EAC countries, we observe that for Proxy 1 (inverse of realized inflation) Burundi and Tanzania, and for Proxy 2 (inverse of public domestic debt to GDP) additionally Kenya, are in favor of entering into such a union. The other countries are only willing to go ahead with such a move when the other benefits associated with a monetary union are of a sufficient magnitude, as expressed by the level of $\kappa^{*}$. Considering Proxy 1, Rwanda is the most reluctant (has the highest level of $\kappa^{*}$ ), whereas for Proxy 2 this place is taken by Uganda. This is in line with our observation in Section 2 that both Rwanda and Uganda had substantial success in reforming their economies in the last decade. When policymakers do properly account for the role of uncertainty in this decision problem, by allowing for the value of the real option introduced by the uncertainty surrounding the benefits from a potential monetary union (driven by the variability in our monetary stability measures observed in Tables 1 and 2), only Burundi and Kenya, and that exclusively for Proxy 2, still want to go ahead with the monetary union. The other three countries for Proxy 2, and all five EAC member countries when focussing on Proxy 1, would now be reluctant to join, with the countries requiring the highest, and now substantially larger, relative levels of other compensating benefits from such a monetary union still being Rwanda when considering Proxy 1, and Uganda when focussing on Proxy 2. Interestingly, we can further note that considering only a monetary union consisting of the original EAC member countries Kenya, Tanzania and Uganda does not change those countries' incentives to join such a narrower monetary union compared to the larger five country union, irrespective of whether policymakers properly account for the role of uncertainty in their decision making or not.

The importance of allowing for the role of uncertainty in policymakers' decision making also shows when we examine countries' willingness to par- 
ticipate in a monetary union based on financial stability motives, the results of which are presented in Table 7. When uncertainty is abstracted from, almost all countries find participation in a monetary union consisting of all five EAC countries beneficial, with the exception of Uganda when considering Proxy 1 (inverse of nonperforming loans to gross loans), and Kenya when examining Proxy 2 (aggregate Z-score). Again this is consistent with our discussion in Section 2 which showed that Kenya and Uganda have the most robust banking systems amongst the group of EAC countries. When uncertainty regarding the evolution of our financial stability measures (see Table 4) is properly accounted for in policymakers' decision problem, Kenya also loses interest in joining the monetary union based on Proxy 1, with Uganda becoming even more strongly opposed to such a move (as shown by its high level of $\kappa^{*}$ ). When considering Proxy 2, however, none of the countries want to move towards the monetary union unless sufficiently compensated by the respective relative other benefits associated with it, with Uganda again being the most demanding in this sense (having the highest level $\kappa^{*}$ ), followed closely by Tanzania. Similarly to the results obtained for the monetary stability criteria above, countries' incentives of joining a narrower monetary union consisting of only the original EAC member countries are unchanged compared to those associated with joining the larger one, again irrespective of whether uncertainty is allowed for in policymakers decision making or not.

A further illustration of how important the consideration of uncertainty is in this context is given when we lastly examine countries' willingness to participate in a monetary union on fiscal stability grounds (Table 8). Results for the no uncertainty case are somewhat mixed, providing an exactly opposing picture of whether or not countries want to join the monetary union consisting of all five EAC member countries depending on whether Proxy 1 (inverse of budget deficit inc. grants to GDP), or Proxy 2 (inverse of budget deficit excl. grants to GDP) is used. This stresses, in a sense, the importance of being careful as to which measure to use in this context; as the latter 
one clearly gives a more "structural" picture of a country's fiscal position, we would favor concentrating on the second one. On this basis, Kenya and Uganda would be opposed to the monetary union on fiscal stability grounds, with the other countries finding it beneficial. These results change dramatically, though, once we consider that policymakers do allow for the role of uncertainty in the fiscal stability measures (see Table 2), in that no country wants to join the wider monetary union when considering Proxy 1 in this case. Only Rwanda finds the move towards the monetary union beneficial when focussing on Proxy 2, with the remaining countries opposed and Uganda again showing the highest level of reticence in this scenario. As for the previous two stability motives considered, countries' decisions of whether or not to join the monetary union are unchanged when only concentrating on the three original EAC member countries, again whether uncertainty is properly accounted for or not.

Overall, we take away two key results from our calibrations: firstly, the choice of proxy for our monetary, financial and fiscal stability measures is not innocuous and does matter; secondly, and more importantly, allowing for the role of uncertainty in measures of monetary, financial and fiscal stability generally makes policymakers' significantly less eager to engage in a monetary union unless compensated for by sufficient degrees of other benefits, such as transactional benefits or, more importantly in our view, institutional improvements. Looking at the monetary stability aspect of our calibrations, and focussing on the arguably more solid, as direct, measure of (realized) inflation, none of the countries wants to engage in a monetary union in the uncertainty scenario unless compensated for by significant relative levels of additional benefits $\kappa^{*}$ ranging between 0.52 (for Tanzania) and 2.16 (for Rwanda). Given the evident current political will to move ahead with a monetary union in the EAC, this in our view calls for a sufficiently robust, credible institutional structure assuring monetary stability in the monetary union beyond what individual central banks are able to 
achieve at the moment. Turning to the financial stability aspect of the question, and concentrating on the aggregate Z-score measure which arguably is more robust than the one relying on often more unreliable non performing loans data, we observe a similar picture: all countries are unwilling to engage in the monetary union when uncertainty is taken into account, unless compensated for by substantial relative levels of additional benefits $\kappa^{*}$ in the range of 0.43 (for Rwanda) and 2.78 (for Uganda). Again, this calls for considerable improvements in the institutional arrangements regarding financial stability in the monetary union area, and given the euro zone countries' recent experience, preferably in a formalized arrangement that is set out right from the start of the monetary union, rather than as more informal ad hoc structures. Lastly, a similar picture again evolves when looking at the fiscal stability aspect examined, where we prefer to focus on the budget deficit (excl. grants) measure as the one most closely reflecting the underlying, structural fiscal position in a country. All countries except possibly Rwanda would be reluctant to join the monetary union from a fiscal stability perspective when uncertainty is taken into account, unless compensated for by relative levels of additional benefits $\kappa^{*}$ ranging from 0.02 (for Burundi) and 0.26 (for Uganda). Compared to the monetary and financial criteria, these additional required relative benefits are fairly small, suggesting that a reasonable amount of credible institutional structure assuring fiscal stability in the monetary union area should suffice to satisfy all potential member countries in this respect.

\section{[Insert Tables 6-8]}

\section{Conclusion}

Our paper aims to contribute to the ongoing academic debate accompanying the current political drive towards the establishment of a monetary union in the East African Community (EAC). Rather than focus more narrowly on the 
discussion of convergence issues for different sets of economic criteria, we use a somewhat different approach that particularly highlights the importance of the role of uncertainty in policymakers' decision making in this context.

To this end, we develop a stylized model of policymakers' decision problem that allows for the stochastic nature of monetary, financial and fiscal stability as three key areas of relevance for the decision to join a monetary union. In addition to the more common monetary stability aspect, the recent upheaval in the euro zone motivates us to also focus on financial and fiscal stability in this context. By characterizing the real option implicit in a policymaker's decision of whether or not to join the monetary union, we derive the trigger values of monetary, financial and fiscal stability measures which drive whether or not policymakers find it beneficial to engage in the monetary union at the moment. We can show that when policymakers properly account for the uncertainty regarding the evolution of these monetary, financial and fiscal stability measures, they might show a substantial degree of reluctance to participate in the monetary union unless compensated for by potential other factors, such as institutional improvements or more standard transactional benefits.

Calibrating our model for the EAC using annual data for the period 2003 to 2010, for various proxies of our respective monetary, financial and fiscal stability measures, we then conclude that when policymakers properly allow for the uncertainty surrounding the evolution of these measures, none of the countries wants to engage in a monetary union based on either monetary or financial stability grounds, and only Rwanda might want to engage in it on fiscal stability grounds, unless compensated for by significant relative levels of additional benefits associated with being in the monetary union. Particularly in the context of the current dramatic euro zone experience, this highlights the importance of agreeing and setting up, from the very start, credible and robust institutional arrangements at the monetary union level assuring substantial improvements in monetary, financial and fiscal stability 
for the countries participating in the monetary union. In our mind this is a key lesson: as we saw in the European case, when the political will to form a monetary union is there, economists' views on whether or not a region forms an optimum currency area are easily swept aside. Our results, supported by the experience of the recent turmoil in the euro zone, suggest that the key to a viable and sustainable monetary union may lie in good institutional foundations, not only supporting monetary stability as such, but also assuring wider financial and fiscal stability as well.

\section{Acknowledgments}

Parts of this study were completed while Clovis Rugemintwari was a visiting researcher in the Department of Economics at University of Birmingham. We are grateful for very helpful comments by Sugata Ghosh, Alex Mandilaras, Alain Sauviat and the participants at the Seventh Annual CEDI Conference at Brunel University; the usual disclaimer applies.

\section{References}

Barro, R. (1983). Inflationary finance under discretion and rules. Canadian Journal of Economics, 16, 1-16.

Barro, R. J., \& Gordon, D. B. (1983a). A positive theory of monetary policy in a natural rate model. Journal of Political Economy, 91, 589-610.

Barro, R. J., \& Gordon, D. B. (1983b). Rules, discretion and reputation in a model of monetary policy. Journal of Monetary Economics, 12, 101-121.

Buigut, S. (2011). A fast-track East African Community Monetary Union? Convergence evidence from a cointegration analysis. International Journal of Economics and Finance, 3, 255-261. 
Buigut, S., \& Valev, N. T. (2009). Benefits from mutual restraint in a multilateral monetary union. World Development, 37, 585-594.

Buigut, S. K., \& Valev, N. T. (2005). Is the proposed East African Monetary Union an optimal currency area? A structural vector autoregression analysis. World Development, 33, 2119-2133.

Cihak, M., \& Podpiera, R. (2005). Bank behavior in developing countries: Evidence from East Africa. IMF Working Paper, WP/05/129.

De Grauwe, P. (2012). Economics of Monetary Union. (9th ed.). Oxford: Oxford University Press.

Debrun, X., Masson, P. R., \& Pattillo, C. (2011). Should African Monetary Unions be expanded? An empirical investigation of the scope for monetary integration in Sub-Saharan Africa. Journal of African Economies, 20, ii104 - ii144.

Dixit, A. K. (1993). The Art of Smooth Pasting (Fundamentals of Pure and Applied Economics Vol. 55). Amsterdam: Harwood Academic Publishers.

Dixit, A. K., \& Pindyck, R. S. (1994). Investment under Uncertainty. Princeton, NJ: Princeton University Press.

EAC (2011). One people. One currency: Negotiations kick off for East African Monetary Union. The Community - The Official Magazine of the EAC. March 2011.

Harrison, M. (2010). Valuing the future: The social discount rate in costbenefit analysis. Productivity Commission, Canberra, Visiting Researcher Paper.

Hazlewood, A. (1979). The end of the East African Community: What are the lessons for regional integration schemes? Journal of Common Market Studies, 18, 40-58. 
Heritage Foundation (2012). Economic Freedom Index - Country Factsheets.

Ingersoll, J. E. (1987). Theory of financial decision making. Totowa NJ: Rowman \& Littlefield.

Kenen, P. B. (1969). The optimum currency area: An eclectic view. In R. Mundell, \& A. Swoboda (Eds.), Monetary Problems of the International Economy. Chicago: University of Chicago Press.

Kishor, N. K., \& Ssozi, J. (2011). Business cycle synchronization in the proposed East African Monetary Union: An unobserved component approach. Review of Development Economics, 15, 664-675.

McKinnon, R. I. (1963). Optimum currency areas. American Economic Review, 53, 717-725.

Mkenda, B. K. (2001). Is East Africa an optimum currency area? Göteborg University Working Paper in Economics, 41.

Mugomba, A. T. (1978). Regional organisations and African underdevelopment: The collapse of the East African Community. The Journal of Modern African Studies, 16, pp. 261-272.

Mundell, R. A. (1961). A theory of optimum currency areas. American Economic Review, 51, 657-665.

Rusuhuzwa, T. K., \& Masson, P. R. (2012). Design and implementation of a common currency area in the East African Community. University of Toronto Economics Working Paper, 451.

Sanya, S., \& Gaertner, M. (2012). Assessing bank competition within the East African Community. IMF Working Paper, WP/12/32.

Strobel, F. (2005). Monetary integration and inflation preferences: A real options analysis. European Economic Review, 49, 845-860. 
Strobel, F. (2007). Joining European Monetary Union: A real options perspective. Scottish Journal of Political Economy, 54, 105-115.

Strobel, F. (2009). Financial fragility and crisis union in the Asia-Pacific Region. Global Economy Journal, 9(2), Art. 7.

Strobel, F. (2011). Bank insolvency risk and different approaches to aggregate Z-score measures: A note. Applied Economics Letters, 18, 1541-1543.

UN Economic Commission for Africa (2008). Assessing financial sector reforms in Eastern Africa: Case of EAC and CEPGL. Technical Report ECA/SRO-EA/ICE/2008/07.

\section{A Appendix}

Proof. (Proposition 1) For country $c$, not participating in the monetary union $u$ for a further instant $d t$ is optimal in the continuation region of the optimal stopping problem eq. (3), giving the relevant Bellman equation as

$$
\mu F\left(B_{s u}, B_{s c}\right)=\frac{1}{d t} E_{t}\left[d F\left(B_{s u}, B_{s c}\right)\right], s=m, f, g
$$

Applying Ito's Lemma to eq. (4) and noting that the value function $F\left(B_{s u}, B_{s c}\right)$ should be homogeneous of degree $1,{ }^{22}$ so that $F\left(B_{s u}, B_{s c}\right)=B_{s c} f\left(\Psi_{s}\right)$ where $\Psi_{s} \equiv B_{s u} / B_{s c}$, we obtain

$$
\begin{array}{r}
\left(\sigma_{s u}^{2}-2 \rho_{s} \sigma_{s u} \sigma_{s c}+\sigma_{s c}^{2}\right) \gamma^{2} \Psi_{s}^{2} f^{\prime \prime}\left(\Psi_{s}\right)+\left(\sigma_{s u}^{2}-\sigma_{s c}^{2}\right) \gamma(\gamma-1) \Psi_{s} f^{\prime}\left(\Psi_{s}\right) \\
+\sigma_{s c}^{2} \gamma(\gamma-1) f\left(\Psi_{s}\right)-2 \mu f\left(\Psi_{s}\right)=0, s=m, f, g
\end{array}
$$

as the differential equation that characterizes the evolution of $f\left(\Psi_{s}\right)$ in that region.

\footnotetext{
${ }^{22}$ This adopts the solution strategy in Dixit \& Pindyck (1994, p. 210).
} 
We solve eq. (5) by standard methods, using the value-matching and smooth-pasting conditions $f\left(\Psi_{s}^{*}\right)=\left(1+\kappa_{s}\right) \Psi_{s}^{*}-1$ and $\partial f\left(\Psi_{s}^{*}\right) / \partial \Psi_{s}=$ $\left(1+\kappa_{s}\right)$ and the boundary condition ${ }^{23} f(0)=0$; we thereby obtain $\Psi_{s}^{*}=$ $\beta_{s}^{+} /\left(\left(1+\kappa_{s}\right)\left(\beta_{s}^{+}-1\right)\right)$ where $\beta_{s}^{+}$is the positive root of the characteristic equation

$$
\begin{aligned}
\left(\sigma_{s u}^{2}-2 \rho_{s} \sigma_{s u} \sigma_{s c}+\sigma_{s c}^{2}\right) \gamma^{2} \beta_{s}^{2}-\left(2 \gamma\left(\sigma_{s c}^{2}-\rho_{s} \sigma_{s u} \sigma_{s c}\right)+\sigma_{s u}^{2}-\sigma_{s c}^{2}\right) \gamma \beta_{s} \\
+\sigma_{s c}^{2} \gamma(\gamma-1)-2 \mu=0, s=m, f, g
\end{aligned}
$$

as the critical (trigger) value $\Psi_{s}^{*}$. From the definition of $\Psi_{s}$ it follows that

$$
\xi_{s u}^{*} / \xi_{s c}^{*}=\left(\frac{\beta_{s}^{+}\left(\mu-\frac{1}{2} \sigma_{s u}^{2} \gamma(\gamma-1)\right)}{\left(1+\kappa_{s}\right)\left(\beta_{s}^{+}-1\right)\left(\mu-\frac{1}{2} \sigma_{s c}^{2} \gamma(\gamma-1)\right)}\right)^{\frac{1}{\gamma}}, s=m, f, g
$$

is the trigger value of relative monetary, financial or fiscal stability measures $\xi_{s u} / \xi_{s c}$ separating the region in $\left(\xi_{s u}, \xi_{s c}\right)$ space where country c's option of participating in the monetary union $u$ remains unexercised (i.e. for $\xi_{s u} / \xi_{s c}<$ $\left.\xi_{s u}^{*} / \xi_{s c}^{*}\right)$ from the one where immediate exercise of that option is perceived as optimal (i.e. for $\xi_{s u} / \xi_{s c} \geq \xi_{s u}^{*} / \xi_{s c}^{*}$ ).

\footnotetext{
${ }^{23}$ The geometric Brownian motion $\Psi_{s}$ has an absorbing barrier at zero.
} 
Figure 1: EAC GDP per capita (constant 2000 US\$)

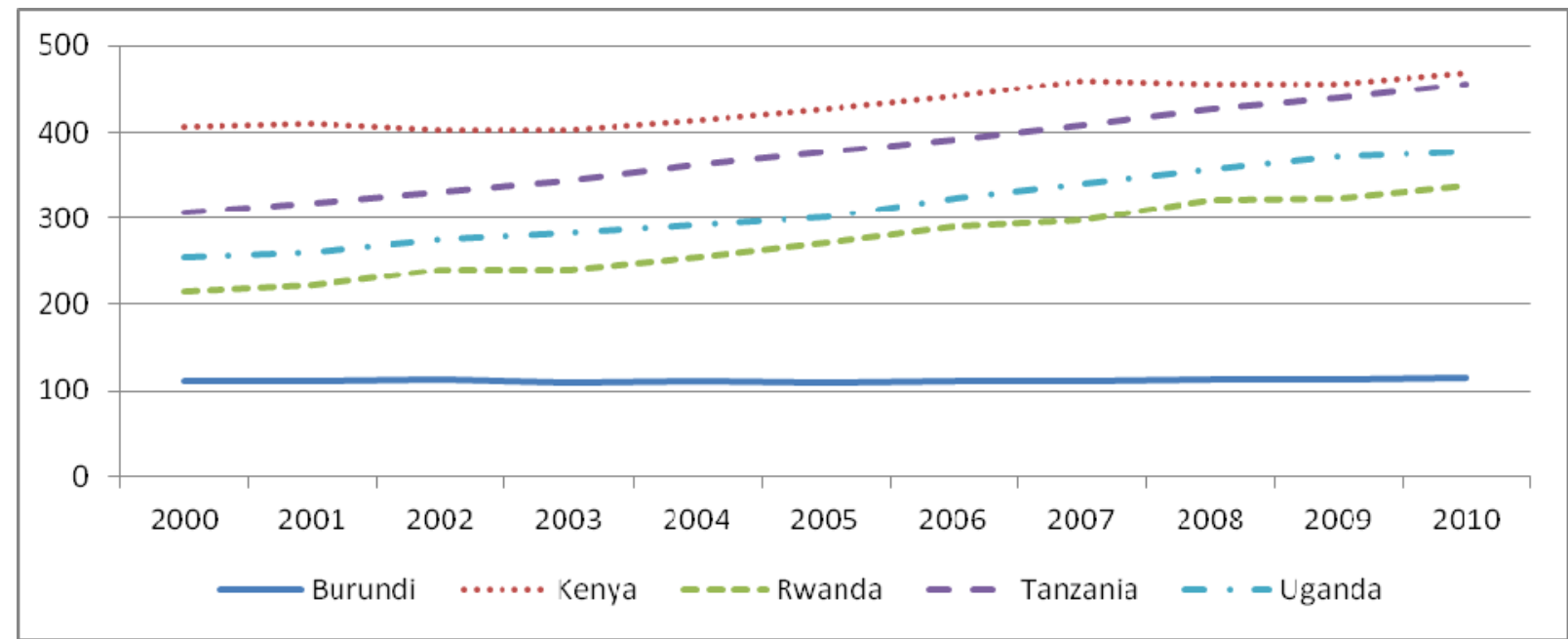

Source: World Bank: World Development Indicators (Edition: April 2012)

Figure 2: EAC government effectiveness

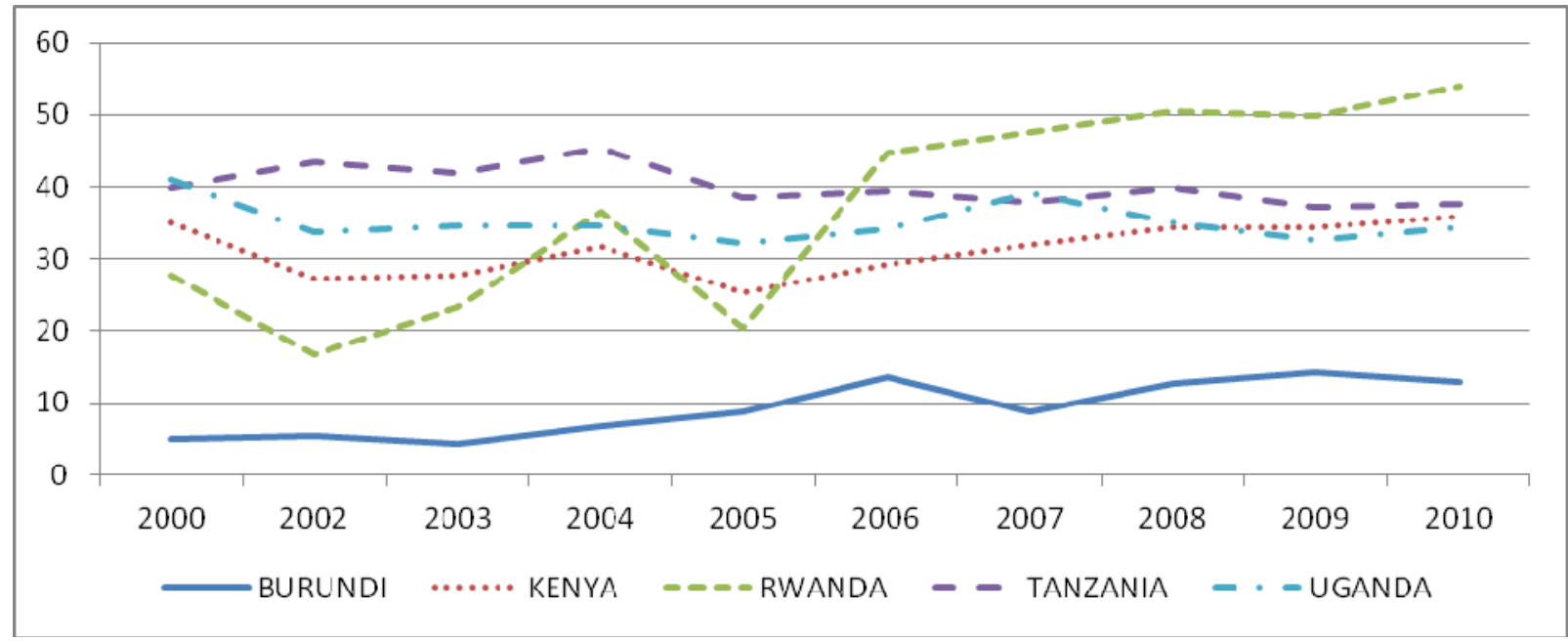

Source: World Bank: Worldwide Governance Indicators (2010)

This indicator captures perceptions of the quality of public services, the quality of the civil service and the degree of its independence from political pressures, the quality of policy formulation and implementation, and the credibility of the government's commitment to such policies. 
Figure 3: EAC control of corruption

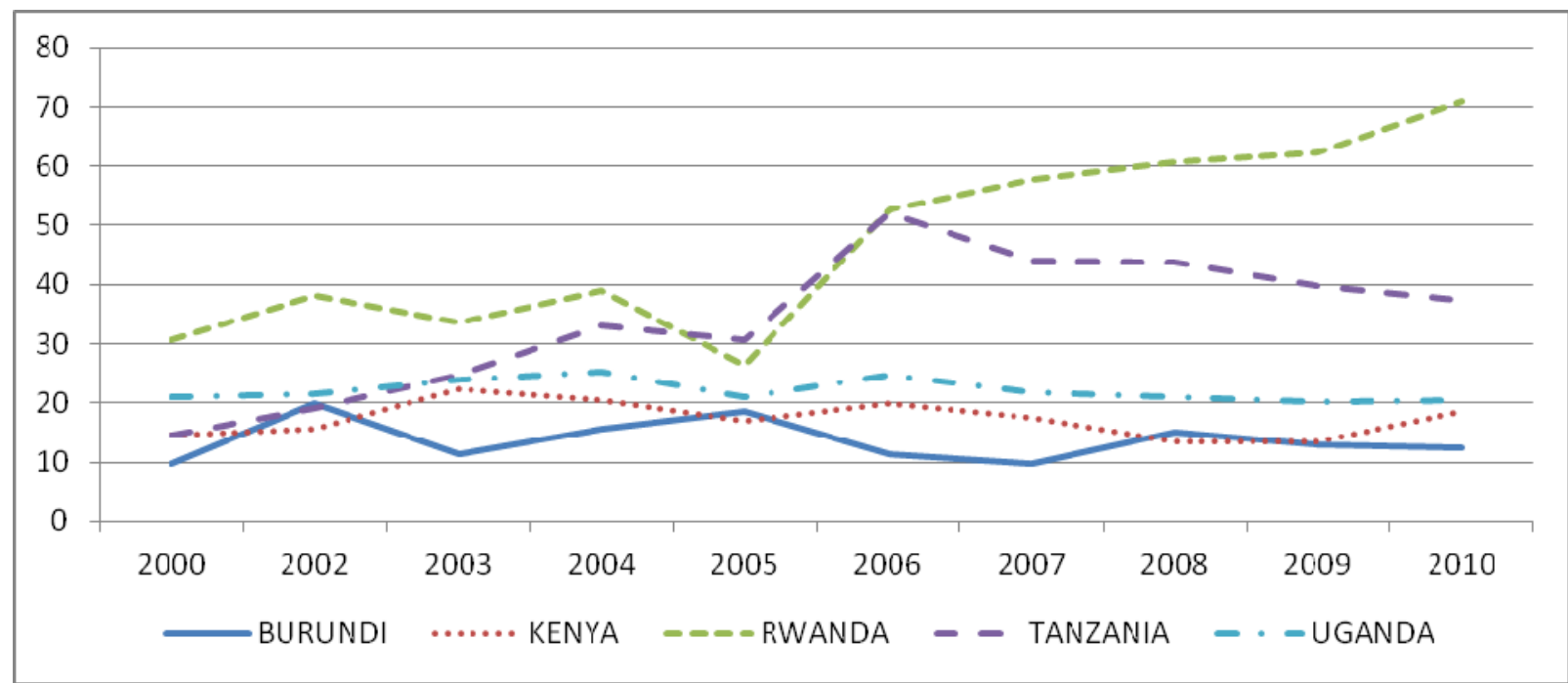

Source: World Bank: Worldwide Governance Indicators (2010)

This indicator captures perceptions of the extent to which public power is exercised for private gain, including both petty and grand forms of corruption, as well as "capture" of the state by elites and private interests.

Figure 4: EAC political stability and absence of violence/terrorism

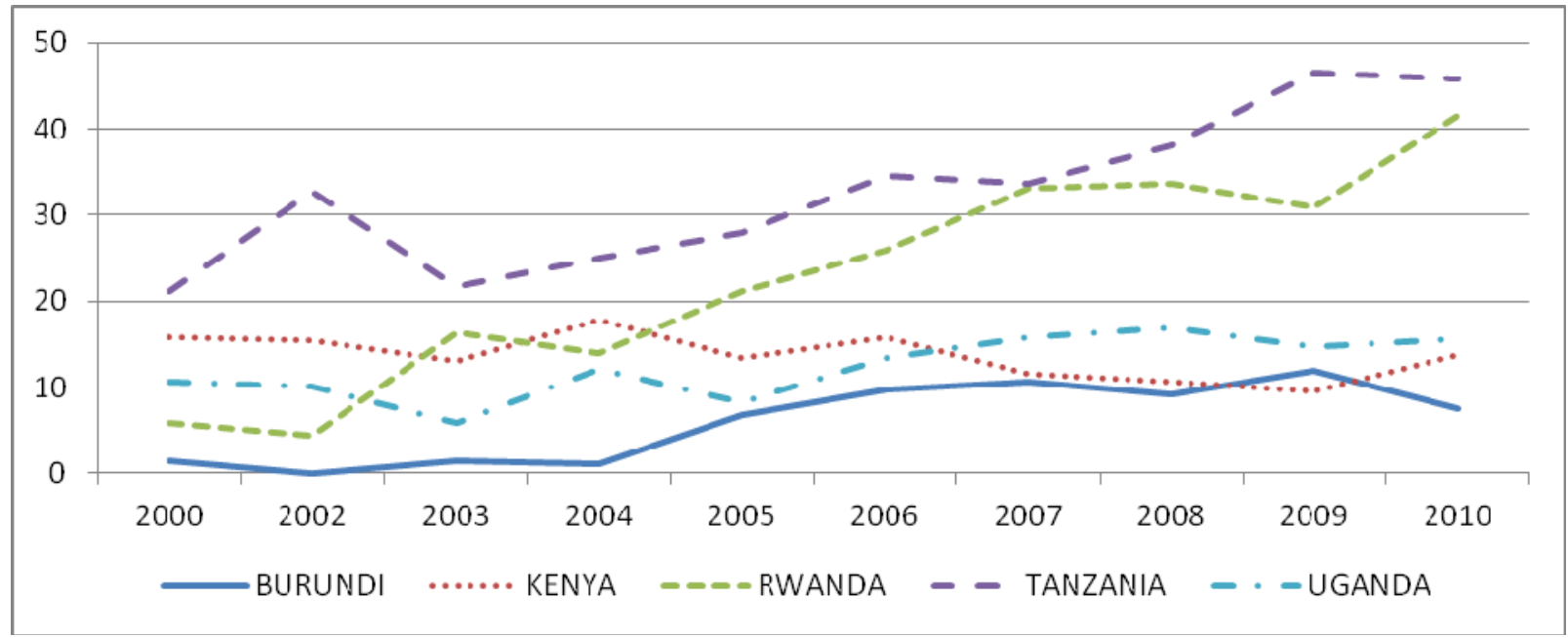

Source: World Bank: Worldwide Governance Indicators (2010)

This indicator captures perceptions of the likelihood that the government will be destabilized or overthrown by unconstitutional or violent means, including politically-motivated violence and terrorism. 
Figure 5: EAC rule of law

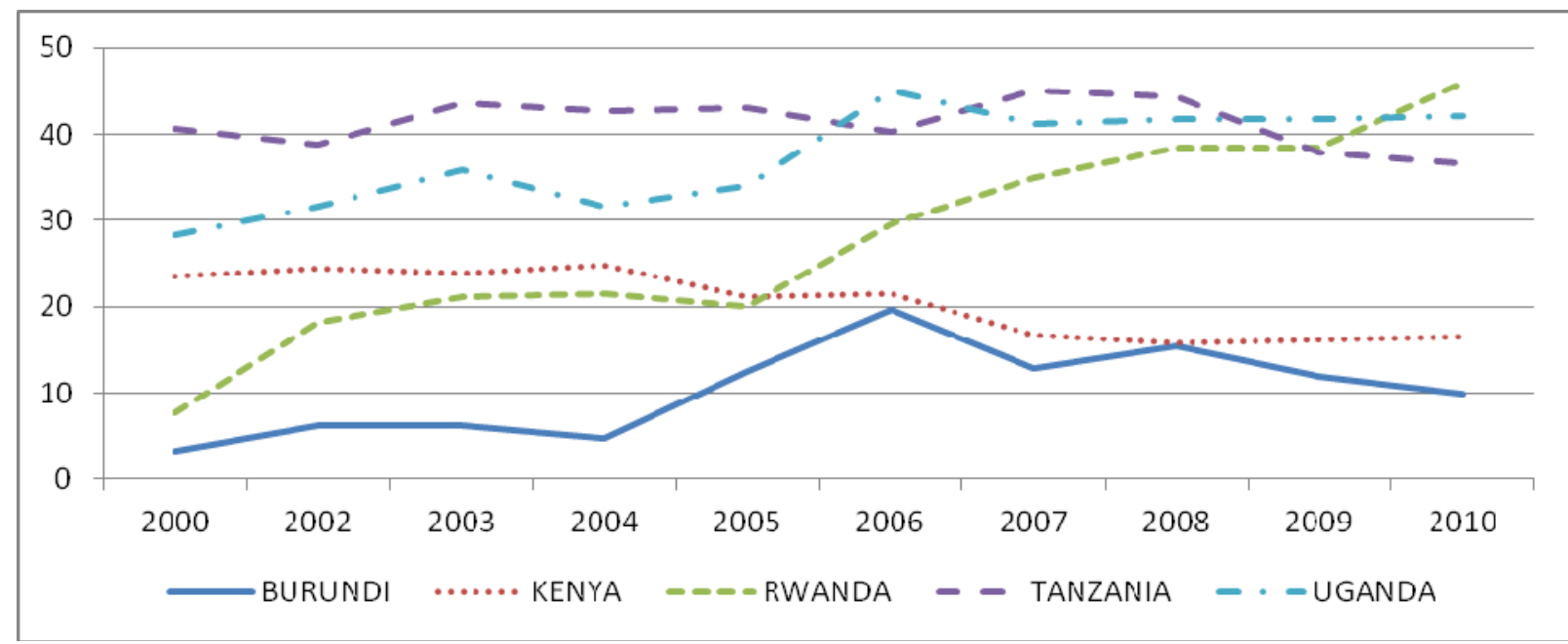

Source: World Bank: Worldwide Governance Indicators (2010)

This indicator captures perceptions of the extent to which agents have confidence in and abide by the rules of society, and in particular the quality of contract enforcement, property rights, the police, and the courts, as well as the likelihood of crime and violence.

Figure 6: EAC regulatory quality

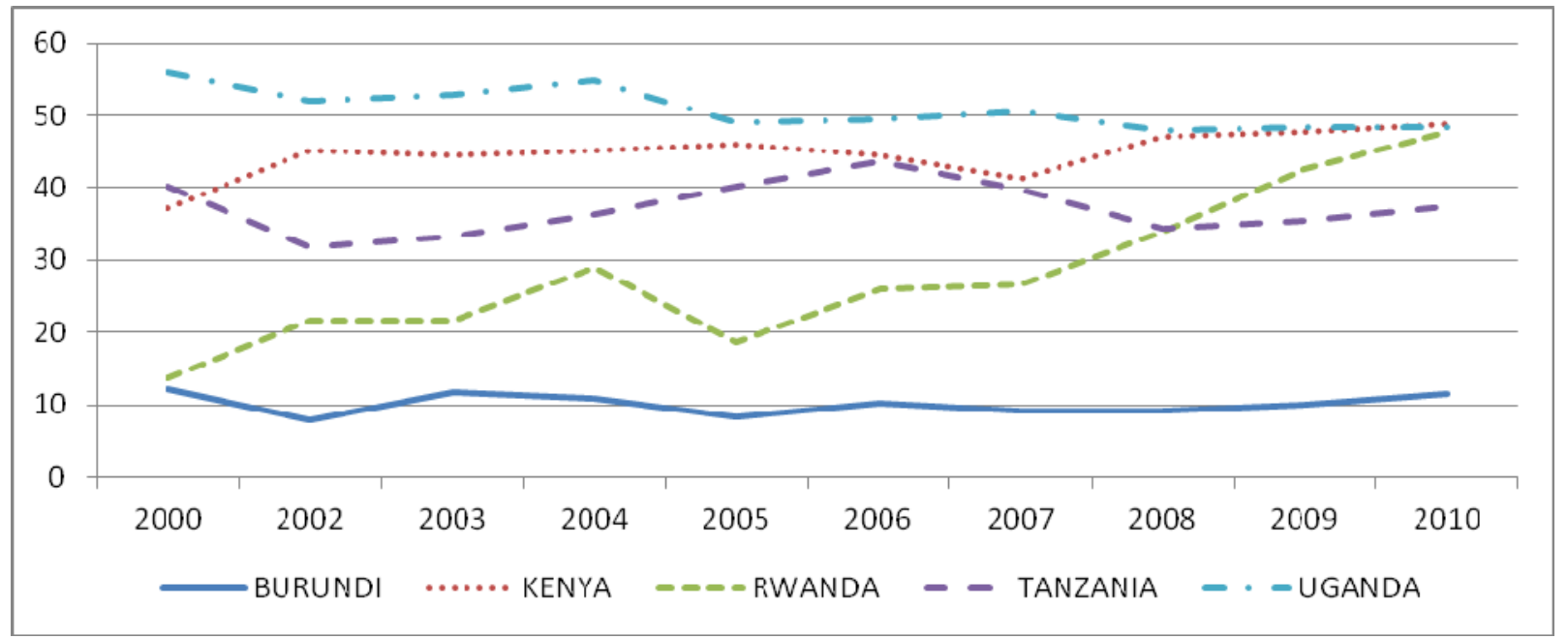

Source: World Bank: Worldwide Governance Indicators (2010)

This indicator captures perceptions of the ability of the government to formulate and implement sound policies and regulations that permit and promote private sector development. 
Figure 7: EAC money and quasi money (M2) as \% of GDP

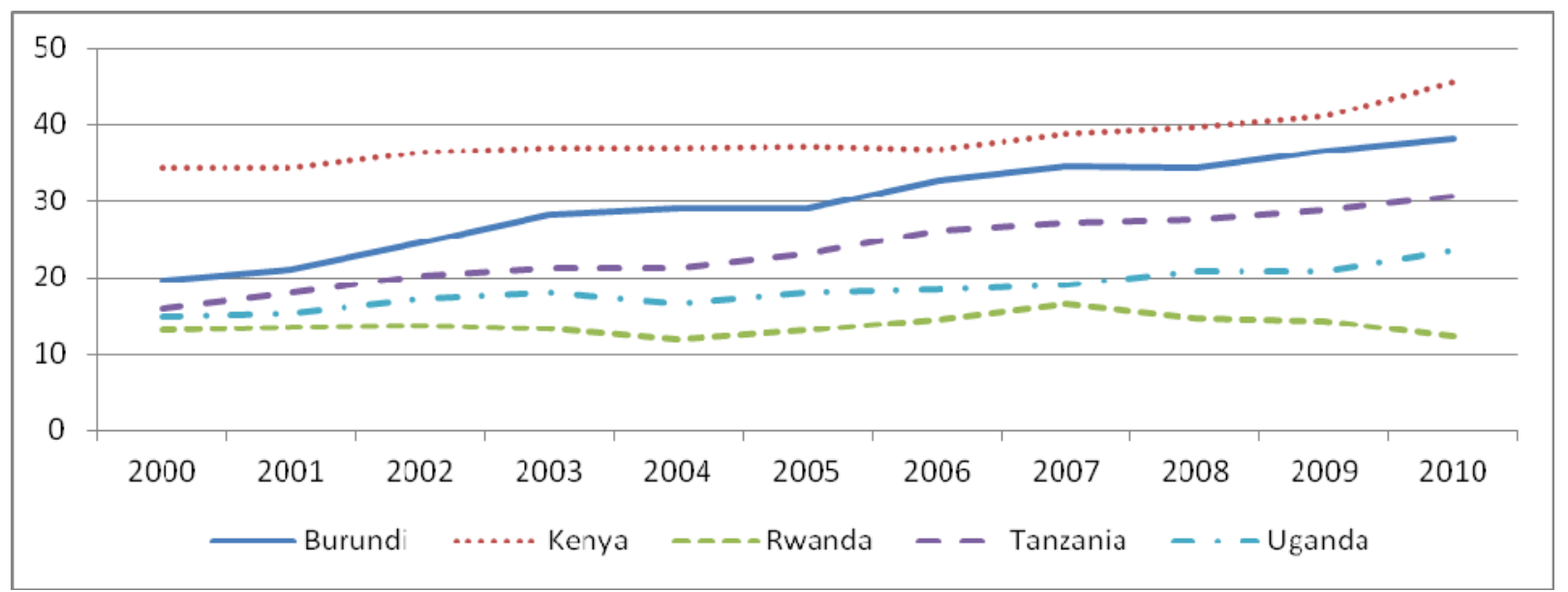

Sources: World Bank (2012): World Development Indicators (Edition: April 2012); East African Community Statistics (2012).

Figure 8: EAC domestic credit provided by banking sector as \% of GDP

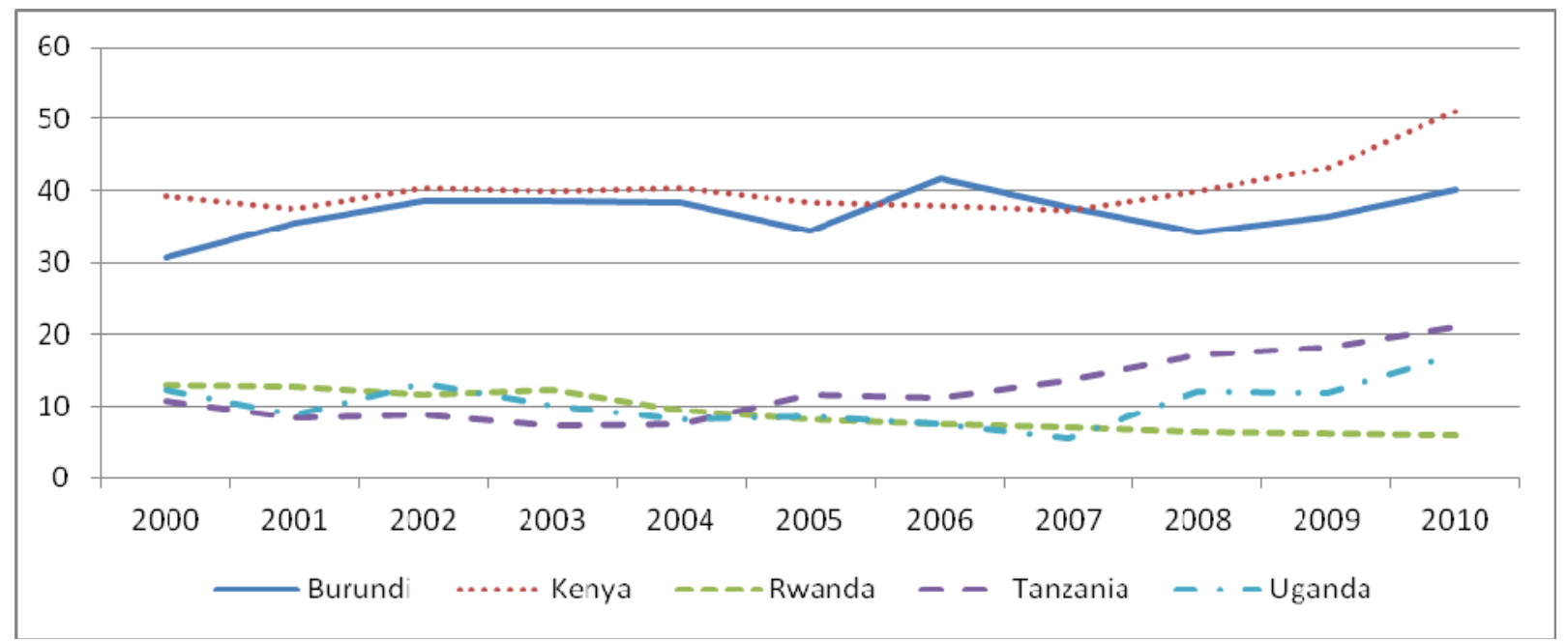

Sources: World Bank (2012): World Development Indicators (Edition: April 2012). 
Figure 9: Trigger value $\xi_{u}^{*} / \xi_{c}^{*}($ for $\rho=0.5, \mu=0.12, \gamma=0.5, \kappa=0$ )

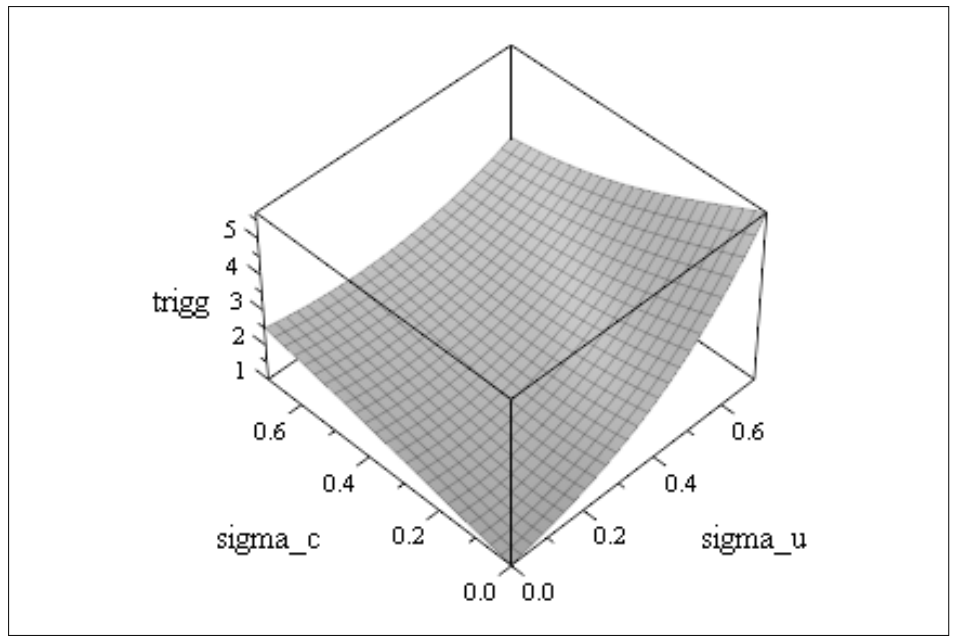

Figure 10: Trigger value $\xi_{u}^{*} / \xi_{c}^{*}\left(\right.$ for $\left.\sigma_{u}=0.4, \sigma_{c}=0.5, \gamma=0.5, \kappa=0\right)$

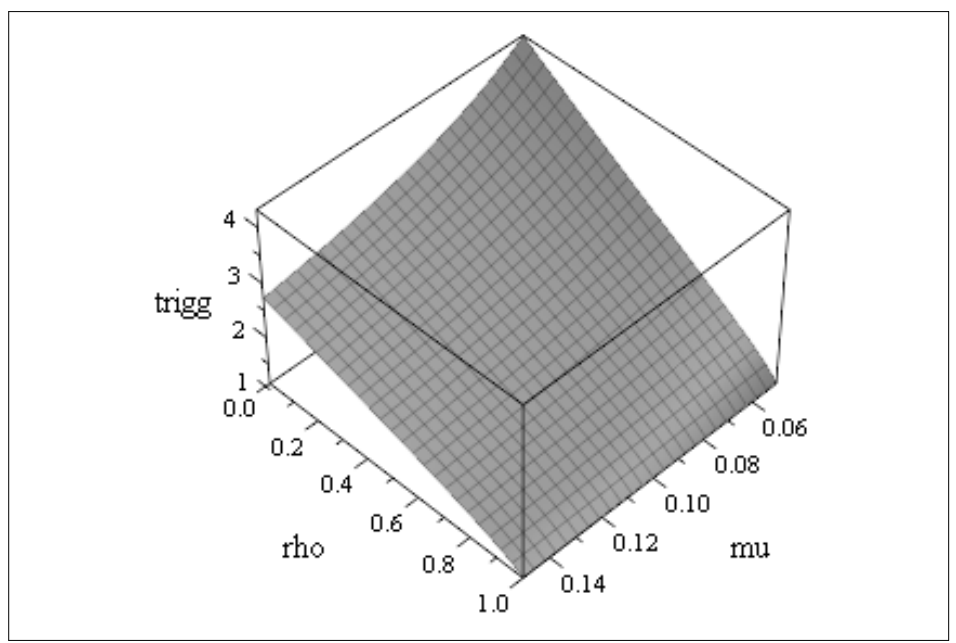


Figure 11: Trigger value $\xi_{u}^{*} / \xi_{c}^{*}\left(\right.$ for $\left.\sigma_{u}=0.4, \sigma_{c}=0.5, \rho=0.5, \mu=0.12\right)$

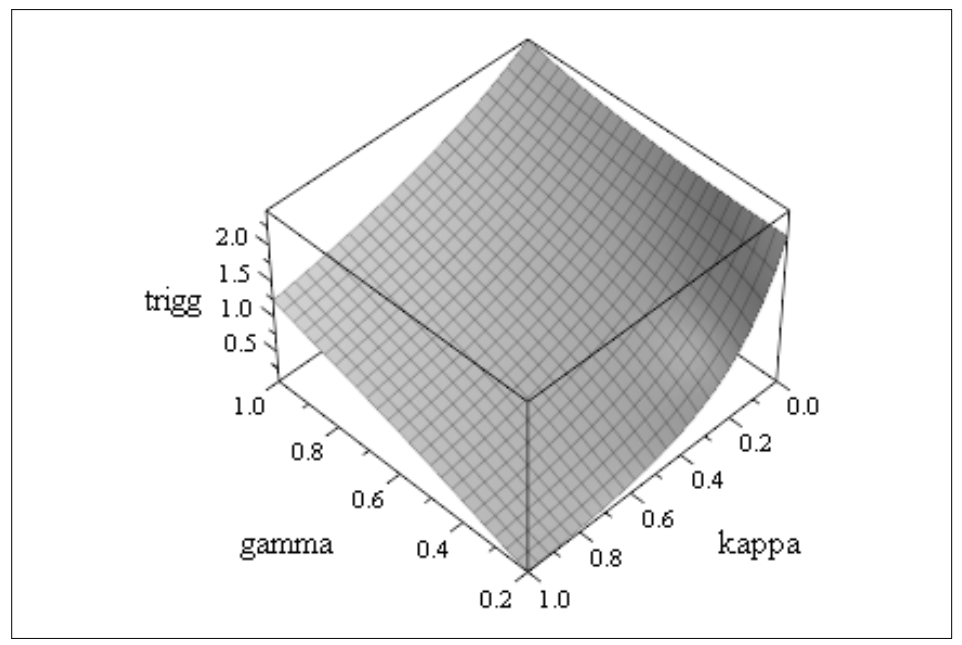


Table 1: EAC indicators of economic structure (2000-2010)

\begin{tabular}{|c|c|c|c|c|c|c|c|}
\hline & 2000 & 2002 & 2004 & 2006 & 2008 & 2010 & Average \\
\hline \multicolumn{8}{|c|}{ GDP growth rate } \\
\hline Burundi & -0.86 & 4.45 & 4.83 & 5.12 & 4.50 & 3.90 & 2.80 \\
\hline Kenya & 0.60 & 0.55 & 5.10 & 6.32 & 1.53 & 5.55 & 3.81 \\
\hline Rwanda & 8.10 & 11.00 & 7.40 & 9.20 & 11.20 & 7.50 & 7.64 \\
\hline Tanzania & 4.93 & 7.16 & 7.83 & 6.74 & 7.44 & 7.04 & 6.78 \\
\hline Uganda & 3.14 & 8.73 & 6.81 & 10.78 & 8.71 & 5.18 & 7.00 \\
\hline \multicolumn{8}{|c|}{ Agriculture, value added (\% of GDP) } \\
\hline Burundi & 40.40 & 40.53 & 40.08 & na & na & 30.00 & 39.24 \\
\hline Kenya & 32.36 & 29.13 & 28.04 & 26.75 & 25.83 & 25.18 & 27.91 \\
\hline Rwanda & 37.19 & 35.49 & 38.56 & 38.44 & 32.38 & 33.85 & 36.43 \\
\hline Tanzania & 33.48 & 32.46 & 33.33 & 30.41 & 29.71 & 28.06 & 31.21 \\
\hline Uganda & 29.38 & 24.90 & 22.92 & 25.59 & 22.74 & 24.25 & 25.51 \\
\hline \multicolumn{8}{|c|}{ Industry, value added (\% of GDP) } \\
\hline Burundi & 18.79 & 18.59 & 18.92 & na & na & na & 19.05 \\
\hline Kenya & 16.92 & 17.41 & 18.23 & 18.50 & 19.77 & 19.82 & 18.39 \\
\hline Rwanda & 13.58 & 13.92 & 13.88 & 13.76 & 14.84 & 14.39 & 13.88 \\
\hline Tanzania & 19.18 & 21.06 & 22.35 & 22.88 & 23.14 & 25.48 & 22.38 \\
\hline Uganda & 22.90 & 24.36 & 22.06 & 24.24 & 27.40 & 25.47 & 24.60 \\
\hline \multicolumn{8}{|c|}{ Services, value added (\% of GDP) } \\
\hline Burundi & 40.81 & 40.87 & 41.00 & na & na & na & 41.71 \\
\hline Kenya & 50.72 & 53.46 & 53.73 & 54.76 & 54.40 & 55.00 & 53.70 \\
\hline Rwanda & 49.23 & 50.58 & 47.56 & 47.81 & 52.78 & 51.75 & 49.69 \\
\hline Tanzania & 47.34 & 46.48 & 44.32 & 46.71 & 47.15 & 46.47 & 46.40 \\
\hline Uganda & 47.72 & 50.74 & 55.02 & 50.17 & 49.86 & 50.28 & 49.89 \\
\hline \multicolumn{8}{|c|}{ Trade (\% of GDP) } \\
\hline Burundi & 27.69 & 28.48 & 43.49 & 57.71 & na & na & 39.34 \\
\hline Kenya & 53.31 & 55.17 & 59.48 & 62.73 & 69.23 & 65.39 & 60.88 \\
\hline Rwanda & 34.37 & 34.32 & 35.89 & 36.34 & 44.62 & 40.56 & 37.11 \\
\hline Tanzania & 33.49 & 37.42 & 45.72 & 58.26 & 63.93 & 63.84 & 50.44 \\
\hline Uganda & 32.75 & 36.28 & 35.46 & 43.63 & 56.26 & 58.31 & 43.78 \\
\hline \multicolumn{8}{|c|}{ Inflation, consumer prices (annual \% change) } \\
\hline Burundi & 24.32 & -1.37 & 8.30 & 2.70 & 24.50 & 6.50 & 10.82 \\
\hline Kenya & 9.98 & 1.96 & 11.60 & 6.00 & 16.20 & 4.08 & 8.30 \\
\hline Rwanda & 3.90 & 1.99 & 11.90 & 8.80 & 15.40 & 2.30 & 7.38 \\
\hline Tanzania & 5.92 & 5.32 & 4.16 & 7.30 & 10.30 & 5.50 & 6.42 \\
\hline Uganda & 3.39 & -0.29 & 3.70 & 7.20 & 12.00 & 4.00 & 5.00 \\
\hline
\end{tabular}

Sources: World Bank (2012): World Development Indicators (Edition: April 2012); East African

Community Statistics (2012). 
Table 2: EAC government finances (2000-2010)

\begin{tabular}{|c|c|c|c|c|c|c|c|}
\hline & 2000 & 2002 & 2004 & 2006 & 2008 & 2010 & Average \\
\hline \multicolumn{8}{|c|}{ Budget (overall) deficit/surplus, excluding grants (\% of GDP) } \\
\hline Burundi & -6.25 & -12.10 & -20.04 & -14.50 & -13.58 & -15.55 & -13.89 \\
\hline Kenya & -4.20 & -3.70 & -9.45 & -7.50 & -7.27 & -8.77 & -6.66 \\
\hline Rwanda & -11.10 & -11.60 & -11.20 & -10.50 & -10.50 & -13.67 & -11.33 \\
\hline Tanzania & -4.53 & -4.10 & -10.19 & -8.33 & -8.20 & -8.91 & -7.92 \\
\hline Uganda & -10.90 & -12.20 & -7.85 & -7.10 & -4.61 & -7.95 & -8.16 \\
\hline \multicolumn{8}{|c|}{ Budget (overall) deficit/surplus, including grants (\% of GDP) } \\
\hline Burundi & -3.15 & -1.32 & -5.56 & -3.14 & -3.09 & -2.64 & -3.13 \\
\hline Kenya & -1.17 & -5.10 & -8.19 & -6.28 & -5.66 & -5.27 & -5.34 \\
\hline Rwanda & -0.32 & -2.50 & -0.20 & -0.20 & 0.43 & -1.56 & -0.85 \\
\hline Tanzania & -1.93 & -0.20 & -4.51 & -2.44 & -3.10 & -3.35 & -2.90 \\
\hline Uganda & -4.60 & -2.00 & -0.48 & -1.91 & -1.67 & -4.84 & -2.56 \\
\hline \multicolumn{8}{|c|}{ Domestic public debt (\% of GDP) } \\
\hline Burundi & 13.33 & 16.64 & 27.41 & 24.35 & 19.65 & 23.16 & 20.76 \\
\hline Kenya & 19.91 & 25.01 & 23.19 & 23.73 & 21.96 & 28.29 & 23.68 \\
\hline Rwanda & 11.67 & 10.71 & 8.95 & 8.80 & 5.79 & 6.77 & 8.78 \\
\hline Tanzania & 10.00 & 7.48 & 6.95 & 9.89 & 8.64 & 10.08 & 8.84 \\
\hline Uganda & 2.83 & 5.54 & 3.54 & 3.60 & 1.95 & 2.66 & 3.36 \\
\hline
\end{tabular}

Sources: East African Community Statistics (2012); Central banks and National Bureau of Statistics. 
Table 3: EAC financial development (2010)

\begin{tabular}{|c|c|c|c|c|c|}
\hline & Burundi & Kenya & Rwanda & Tanzania & Uganda \\
\hline \multicolumn{6}{|c|}{ Access to financial services (\%) } \\
\hline Formal & na & 40 & 21 & 17 & 28 \\
\hline Informal & na & 27 & 26 & 27 & 42 \\
\hline Excluded entirely & na & 33 & 52 & 56 & 30 \\
\hline \multicolumn{6}{|c|}{ Number of commercial banks } \\
\hline Domestic banks & 7 & 31 & 9 & 17 & 8 \\
\hline Foreign banks & 0 & 12 & 3 & 16 & 14 \\
\hline \multicolumn{6}{|c|}{ Bank deposits (\% of GDP) } \\
\hline & 34 & 51 & 18 & 29 & 23 \\
\hline \multicolumn{6}{|c|}{ Interest rate spread (lending - deposit rate) } \\
\hline & na & 9.81 & 7.98 & 7.98 & 12.48 \\
\hline \multicolumn{6}{|c|}{ Market capitalization (\% of GDP) } \\
\hline & - & 35.17 & - & 5.51 & 23.69 \\
\hline \multicolumn{6}{|c|}{ Listed domestic companies, total } \\
\hline & - & 55 & - & 11 & 8 \\
\hline
\end{tabular}

Sources: World Bank (2012): World Development Indicators (Edition: April 2012); Finscope (2010); Central banks. 
Table 4: EAC banking system indicators (2003-2010)

\begin{tabular}{|c|c|c|c|c|c|c|c|c|c|}
\hline & 2003 & 2004 & 2005 & 2006 & 2007 & 2008 & 2009 & 2010 & Average \\
\hline \multicolumn{10}{|c|}{ Return on assets (\%) } \\
\hline Burundi & 1.52 & 1.35 & 1.43 & 1.53 & 1.79 & 1.88 & 2.01 & 1.78 & 1.66 \\
\hline Kenya & 1.65 & 1.74 & 2.18 & 2.34 & 2.72 & 3.02 & 3.14 & 3.28 & 2.51 \\
\hline Rwanda & 2.55 & 1.35 & 1.13 & 0.96 & 1.26 & 2.11 & 1.93 & 1.81 & 1.64 \\
\hline Tanzania & 1.71 & 2.27 & 2.96 & 3.74 & 4.39 & 4.48 & 4.19 & 3.47 & 3.40 \\
\hline Uganda & 4.31 & 3.98 & 3.88 & 3.75 & 3.46 & 3.59 & 3.52 & 3.09 & 3.70 \\
\hline \multicolumn{10}{|c|}{ Capital adequacy ratio (\%) } \\
\hline Burundi & 15.08 & 14.80 & 18.29 & 15.50 & 14.10 & 14.68 & 17.88 & 18.80 & 16.14 \\
\hline Kenya & 17.59 & 16.84 & 16.43 & 17.03 & 17.70 & 18.67 & 19.68 & 19.50 & 17.93 \\
\hline Rwanda & 9.00 & 10.60 & 9.58 & 11.39 & 8.16 & 11.53 & 19.61 & 19.50 & 12.42 \\
\hline Tanzania & 21.00 & 21.20 & 16.38 & 17.43 & 17.59 & 16.98 & 19.54 & 20.52 & 18.83 \\
\hline Uganda & 20.89 & 18.93 & 18.86 & 18.66 & 19.31 & 20.15 & 21.66 & 21.45 & 19.99 \\
\hline \multicolumn{10}{|c|}{ Equity to total assets ratio (\%) } \\
\hline Burundi & 9.96 & 9.31 & 8.89 & 9.29 & 9.13 & 9.08 & 11.03 & 12.18 & 9.86 \\
\hline Kenya & 11.77 & 11.36 & 11.89 & 11.73 & 11.64 & 12.30 & 13.07 & 12.85 & 12.08 \\
\hline Rwanda & 8.70 & 9.00 & 8.65 & 9.15 & 9.78 & 10.93 & 13.95 & 12.43 & 10.32 \\
\hline Tanzania & 9.90 & 10.20 & 7.65 & 7.87 & 8.78 & 9.46 & 11.22 & 11.84 & 9.62 \\
\hline Uganda & 9.79 & 10.06 & 9.86 & 11.02 & 11.02 & 12.28 & 13.63 & 14.65 & 11.54 \\
\hline \multicolumn{10}{|c|}{ Non performing loans to gross loans (\%) } \\
\hline Burundi & 17.65 & 20.69 & 19.85 & 20.19 & 18.85 & 16.25 & 14.36 & 11.33 & 17.40 \\
\hline Kenya & 35.78 & 23.88 & 26.15 & 22.07 & 14.39 & 9.39 & 8.51 & 7.14 & 18.41 \\
\hline Rwanda & 8.70 & 9.00 & 8.65 & 9.15 & 9.78 & 12.61 & 13.48 & 12.10 & 10.43 \\
\hline Tanzania & 4.50 & 4.40 & 5.00 & 6.52 & 7.40 & 6.35 & 7.00 & 7.07 & 6.03 \\
\hline Uganda & 6.60 & 3.25 & 2.64 & 2.74 & 3.60 & 3.48 & 3.44 & 2.90 & 3.58 \\
\hline \multicolumn{10}{|c|}{ Aggregate Z-score } \\
\hline Burundi & 75.46 & 36.17 & 23.99 & 22.63 & 107.81 & 45.78 & 57.72 & 21.18 & 48.84 \\
\hline Kenya & 21.31 & 20.27 & 79.03 & 37.92 & 35.94 & 55.09 & 177.48 & 63.99 & 61.38 \\
\hline Rwanda & 17.09 & 9.33 & 11.73 & 17.78 & 20.55 & 12.51 & 11.77 & 11.60 & 14.05 \\
\hline Tanzania & 24.49 & 20.81 & 13.69 & 15.86 & 25.78 & 38.96 & 21.61 & 19.35 & 22.57 \\
\hline Uganda & 11.95 & 21.03 & 16.82 & 16.63 & 35.24 & 68.09 & 54.58 & 35.20 & 32.44 \\
\hline
\end{tabular}

Sources: East African Community Statistics (2012).

Aggregate Z-scores are calculated as $\mathrm{Z}=(\mathrm{ROA}+\mathrm{EQTA}) / \mathrm{SDROA}$, where ROA and EQTA are three year rolling means of the return on assets and the equity to total assets ratio, and SDROA is the three year rolling standard deviation of the return on assets. Higher aggregate Z-scores reflect lower levels of aggregate bank insolvency risk. 
Table 5: EAC banking regulation (2010)

\begin{tabular}{|cccccc|}
\hline & Burundi & Kenya & Rwanda & Tanzania & Uganda \\
\hline Explicit deposit insurance system & & & & \\
\hline \multicolumn{7}{r}{ No } & Yes & No & Yes & Yes \\
\hline Required capital adequacy ratio (\%) & & & & \\
\hline Total & 8 & 12 & 15 & 12 & 12 \\
Core Tier 1 & - & 8 & 10 & & \\
\hline Activity restriction & & & & & \\
\hline Securities activities & Unrestricted & Restricted & Unrestricted & Unrestricted & Restricted \\
Insurance activities & Prohibited & Prohibited & Unrestricted & Permitted & Prohibited \\
Real estate activities & Restricted & Permitted & Permitted & Permitted & Permitted \\
\hline Supervisory power to declare insolvency of a bank & & & \\
\hline \multicolumn{7}{c}{ No } & Yes & Yes & Yes & Yes \\
\hline
\end{tabular}

Sources: World Bank (2012): Bank Regulation and Supervision Database; Central banks. 
Table 6: Willingness to participate in monetary union: Monetary stability motives

\begin{tabular}{|c|c|c|c|c|c|c|c|c|c|c|c|c|}
\hline \multicolumn{13}{|c|}{ Proxy 1 : Inverse of (realized) inflation rate } \\
\hline \multicolumn{7}{|c|}{ All EAC member countries } & \multicolumn{6}{|c|}{$\begin{array}{c}\text { Original EAC member countries } \\
\end{array}$} \\
\hline \multicolumn{4}{|c|}{ No Uncertainty } & \multicolumn{3}{|c|}{ Uncertainty } & \multicolumn{3}{|c|}{ No Uncertainty } & \multicolumn{3}{|c|}{ Uncertainty } \\
\hline Country & Ratio (2010) & Join MU? & $\kappa^{*}$ & Trigger ratio & Join MU? & $\kappa^{*}$ & Ratio (2010) & Join MU? & $\kappa^{*}$ & Trigger ratio & Join MU? & $\kappa^{*}$ \\
\hline Burundi & 1.52 & Yes & & \begin{tabular}{l|l}
2.82 \\
\end{tabular} & No & 0.85 & & & & & & \\
\hline Rwanda & 0.54 & No & 0.86 & 1.70 & No & 2.16 & & & & & & \\
\hline Kenya & 0.96 & No & 0.05 & 1.59 & No & 0.66 & 0.91 & No & 0.10 & 1.61 & No & 0.77 \\
\hline Tanzania & 1.29 & Yes & & 1.96 & No & 0.52 & 1.22 & Yes & & 1.93 & No & 0.58 \\
\hline Uganda & 0.94 & No & 0.07 & 1.77 & No & 0.89 & 0.89 & No & 0.13 & 1.75 & No & 0.97 \\
\hline \multicolumn{13}{|c|}{ Proxy 2: Inverse of Public Domestic Debt to GDP ratio } \\
\hline \multicolumn{7}{|c|}{\begin{tabular}{l|l} 
All EAC member countries & \\
\end{tabular}} & \multicolumn{6}{|c|}{ Original EAC member countries } \\
\hline & & \multicolumn{2}{|c|}{ No Uncertainty } & \multicolumn{3}{|c|}{ Uncertainty } & & \multicolumn{2}{|c|}{ No Uncertainty } & \multicolumn{3}{|c|}{ Uncertainty } \\
\hline Country & Ratio (2010) & Join MU? & $\kappa^{*}$ & Trigger ratio & Join MU? & $\kappa^{*}$ & Ratio (2010) & Join MU? & $\kappa^{*}$ & Trigger ratio & Join MU? & $\kappa^{*}$ \\
\hline Burundi & 3.29 & Yes & & 2.08 & Yes & & & & & & & \\
\hline Rwanda & 0.96 & No & 0.04 & 1.73 & No & 0.80 & & & & & & \\
\hline Kenya & 4.02 & Yes & & 1.84 & Yes & & 4.81 & Yes & & 1.88 & Yes & \\
\hline Tanzania & 1.43 & Yes & & 1.81 & No & 0.26 & 1.71 & Yes & & 1.84 & No & 0.07 \\
\hline Uganda & 0.38 & No & 1.64 & 1.33 & No & 2.53 & 0.45 & No & 1.21 & 1.31 & $\mathrm{No}$ & 1.90 \\
\hline
\end{tabular}

Sources: EAC Statistics database, central banks' reports, IMF's IFS and World Bank's WDI. Period: 2003-2010. Values for trigger ratios $\left(\xi_{\mathrm{u}}{ }^{*} / \xi_{\mathrm{c}}{ }^{*}\right)$ and the minimum level of relative other benefits $\kappa^{*}$ associated with being in a monetary union that makes joining the monetary union worthwhile are derived from Proposition 1 , assuming discount rate $\mu=12 \%$ and concavity factor $\gamma=0.5$. 
Table 7: Willingness to participate in monetary union: Financial stability motives

\begin{tabular}{|c|c|c|c|c|c|c|c|c|c|c|c|c|}
\hline \multicolumn{13}{|c|}{ Proxy 1 : Inverse of Bank Nonperforming Loans to Gross Loans ratio } \\
\hline \multicolumn{7}{|c|}{ All EAC member countries } & \multicolumn{6}{|c|}{ Original EAC member countries } \\
\hline \multicolumn{4}{|c|}{ No Uncertainty } & \multicolumn{3}{|c|}{ Uncertainty } & \multicolumn{3}{|c|}{ No Uncertainty } & \multicolumn{3}{|c|}{ Uncertainty } \\
\hline Country & Ratio (2010) & Join MU? & $\kappa^{*}$ & Trigger ratio & Join MU? & $\kappa^{*}$ & Ratio (2010) & Join MU? & $\kappa^{*}$ & Trigger ratio & Join MU? & $\kappa^{*}$ \\
\hline Burundi & \begin{tabular}{|l|}
1.87 \\
\end{tabular} & Yes & & \begin{tabular}{l|l}
1.53 \\
\end{tabular} & Yes & & & & & & & \\
\hline Rwanda & 1.99 & Yes & & 1.58 & Yes & & & & & & & \\
\hline Kenya & 1.18 & Yes & & 1.43 & No & 0.21 & 1.20 & Yes & & 1.19 & No & 0.20 \\
\hline Tanzania & 1.16 & Yes & & 1.12 & Yes & & 1.18 & Yes & & 7.18 & Yes & \\
\hline Uganda & 0.48 & No & 1.09 & 1.54 & No & 2.23 & 0.49 & No & 1.06 & 5.34 & No & 2.14 \\
\hline \multicolumn{13}{|c|}{ Proxy 2 : Aggregate Z-score measures } \\
\hline \multicolumn{7}{|c|}{ All EAC member countries } & \multicolumn{6}{|c|}{ Original EAC member countries } \\
\hline & & \multicolumn{2}{|c|}{ No Uncertainty } & \multicolumn{3}{|c|}{ Uncertainty } & & \multicolumn{2}{|c|}{ No Uncertainty } & \multicolumn{3}{|c|}{ Uncertainty } \\
\hline Country & Ratio (2010) & \begin{tabular}{|l|} 
Join MU? \\
\end{tabular} & $\kappa^{*}$ & Trigger ratio & Join MU? & $\kappa^{*}$ & Ratio (2010) & Join MU? & $\kappa^{*}$ & Trigger ratio & Join MU? & $\kappa^{*}$ \\
\hline Burundi & 2.25 & Yes & & \begin{tabular}{l|}
4.05 \\
\end{tabular} & No & 0.80 & & & & & & \\
\hline Rwanda & 4.10 & Yes & & 5.88 & No & 0.43 & & & & & & \\
\hline Kenya & 0.74 & $\mathrm{No}$ & 0.34 & 1.22 & $\mathrm{No}$ & 0.64 & 0.76 & No & 0.31 & 1.19 & $\mathrm{No}$ & 0.56 \\
\hline Tanzania & 2.46 & Yes & & 6.80 & $\mathrm{No}$ & 1.77 & 2.52 & Yes & & 7.18 & No & 1.85 \\
\hline Uganda & 1.35 & Yes & & 5.12 & No & 2.78 & 1.38 & Yes & & 5.34 & $\mathrm{No}$ & 2.86 \\
\hline
\end{tabular}

Sources: EAC Statistics database, central banks' reports, IMF's IFS and World Bank's WDI. Period: 2003-2010. Values for trigger ratios $\left(\xi_{\mathrm{u}}{ }^{*} / \xi_{\mathrm{c}}{ }^{*}\right.$ ) and the minimum level of relative other benefits $\kappa^{*}$ associated with being in a monetary union that makes joining the monetary union worthwhile are derived from Proposition 1, assuming discount rate $\mu=12 \%$ and concavity factor $\gamma=0.5$. 
Table 8: Willingness to participate in monetary union: Fiscal stability motives

\begin{tabular}{|c|c|c|c|c|c|c|c|c|c|c|c|c|}
\hline \multicolumn{13}{|c|}{ Proxy 1 : Inverse of budget deficit (incl. grants) to GDP ratio } \\
\hline \multicolumn{7}{|c|}{ All EAC member countries } & \multicolumn{6}{|c|}{ Original EAC member countries } \\
\hline \multicolumn{4}{|c|}{ No Uncertainty } & \multicolumn{3}{|c|}{ Uncertainty } & \multicolumn{3}{|c|}{ No Uncertainty } & \multicolumn{3}{|c|}{ Uncertainty } \\
\hline Country & Ratio (2010) & Join MU? & $\kappa^{*}$ & Trigger ratio & Join MU? & $\kappa^{*}$ & Ratio (2010) & Join MU? & $\kappa^{*}$ & Trigger ratio & Join MU? & $\kappa^{*}$ \\
\hline Burundi & 0.89 & No & 0.13 & \begin{tabular}{|l|l}
1.33 & \\
\end{tabular} & No & 0.50 & & & & & & \\
\hline Rwanda & 0.81 & No & 0.23 & 1.36 & No & 0.68 & & & & & & \\
\hline Kenya & 1.07 & Yes & & 1.24 & No & 0.16 & 1.05 & Yes & & 1.25 & $\mathrm{No}$ & 0.20 \\
\hline Tanzania & 0.96 & $\mathrm{No}$ & 0.04 & 1.28 & No & 0.33 & 0.95 & $\mathrm{No}$ & 0.06 & 1.26 & $\mathrm{No}$ & 0.33 \\
\hline Uganda & 1.04 & Yes & & 1.26 & $\mathrm{No}$ & 0.21 & 1.02 & Yes & & 1.29 & No & 0.26 \\
\hline \multicolumn{13}{|c|}{ Proxy 2 : Inverse of budget deficit (excl. grants) to GDP ratio } \\
\hline \multicolumn{7}{|c|}{\begin{tabular}{l|l} 
All EAC member countries & \\
\end{tabular}} & \multicolumn{6}{|c|}{ Original EAC member countries } \\
\hline & & \multicolumn{2}{|c|}{ No Uncertainty } & \multicolumn{3}{|c|}{ Uncertainty } & & \multicolumn{2}{|c|}{ No Uncertainty } & \multicolumn{3}{|c|}{ Uncertainty } \\
\hline Country & Ratio (2010) & Join MU? & $\kappa^{*}$ & Trigger ratio & Join MU? & $\kappa^{*}$ & Ratio (2010) & Join MU? & $\kappa^{*}$ & Trigger ratio & Join MU? & $\kappa^{*}$ \\
\hline Burundi & 1.34 & Yes & & 1.36 & No & 0.02 & & & & & & \\
\hline Rwanda & 1.24 & Yes & & 1.19 & Yes & & & & & & & \\
\hline Kenya & 0.98 & No & 0.02 & 1.16 & No & 0.18 & 0.99 & No & 0.01 & 2.28 & $\mathrm{No}$ & 1.28 \\
\hline Tanzania & 1.01 & Yes & & 1.23 & No & 0.21 & 1.03 & Yes & & 2.14 & No & 1.08 \\
\hline Uganda & 0.93 & No & 0.07 & 1.18 & No & 0.26 & 0.96 & No & 0.06 & 2.06 & No & 1.15 \\
\hline
\end{tabular}

Sources: EAC Statistics database, central banks' reports, IMF's IFS and World Bank's WDI. Period: 2003-2010. Values for trigger ratios $\left(\xi_{\mathrm{u}}{ }^{*} / \xi_{\mathrm{c}}{ }^{*}\right)$ and the minimum level of relative other benefits $\kappa^{*}$ associated with being in a monetary union that makes joining the monetary union worthwhile are derived from Proposition 1, assuming discount rate $\mu=12 \%$ and concavity factor $\gamma=0.5$. 